\title{
Recent Progress in the Development of Fluorescent Probes for Thiophenol
}

\author{
Yuanqiang Hao ${ }^{1,2, *}$, Qianye Yin ${ }^{2}$, Yintang Zhang ${ }^{1}$, Maotian $\mathrm{Xu}{ }^{1,3}$ and Shu Chen ${ }^{2, *}$
}

1 Henan Key Laboratory of Biomolecular Recognition and Sensing, College of Chemistry and Chemical Engineering, Henan Joint International Research Laboratory of Chemo/Biosensing and Early Diagnosis of Major Diseases, Shangqiu Normal University, Shangqiu 476000, China; zhangyintang@sqnu.edu.cn (Y.Z.); xumaotian@sqnu.edu.cn (M.X.)

2 Key Laboratory of Theoretical Organic Chemistry and Function Molecule of Ministry of Education, School of Chemistry and Chemical Engineering, Hunan University of Science and Technology, Xiangtan 411201, China; yinqy083@nenu.edu.cn

3 College of Chemistry and Molecular Engineering, Zhengzhou University, Zhengzhou 450001, China

* Correspondence: haoyuanqiang@aliyun.com (Y.H.); chenshumail@gmail.com (S.C.); Tel.: +86-0370-3112844 (Y.H.)

Received: 1 October 2019; Accepted: 14 October 2019; Published: 16 October 2019

\begin{abstract}
Thiophenol (PhSH) belongs to a class of highly reactive and toxic aromatic thiols with widespread applications in the chemical industry for preparing pesticides, polymers, and pharmaceuticals. In this review, we comprehensively summarize recent progress in the development of fluorescent probes for detecting and imaging PhSH. These probes are classified according to recognition moieties and are detailed on the basis of their structures and sensing performances. In addition, prospects for future research are also discussed.
\end{abstract}

Keywords: fluorescent probes; thiophenol; review

\section{Introduction}

Thiophenol (PhSH) and its derivatives are highly reactive aromatic thiols which care extensively used in the chemical industry for preparing pesticides, polymers, and pharmaceuticals [1-3]. Despite its critical and widespread usage, $\mathrm{PhSH}$ is also highly toxic to organisms. Animal model studies revealed a median lethal concentration of $0.01-0.4 \mathrm{mM}$ for fish and a median lethal dose of $6.2 \mathrm{mg} / \mathrm{kg}$ in mouse [4,5]. Exposure to PhSH can cause serious health problems to the human body including shortness of breath, muscular weakness, kidney and liver malfunctions, central nervous injuries, and even death. Thus, it is of great importance to develop highly sensitive and selective methods for monitoring PhSH in environmental and biological systems.

Analytical assay-based synthetic fluorescent probes are highly attractive and versatile for the detection of biologically and/or environmentally important species because of their high selectivity sensitive, ease of operation, tunable photophysical properties, etc. [6-12]. In recent years, significant progress was made in this field, and numerous effective fluorescent probes were developed for sensing and imaging applications [13-29]. Thiols (including biothiol, hydrogen sulfide, and thiophenol) are important compounds with some unique properties such as strong nucleophilicity, coordination ability, and reducing capacity [30-42]. By exploiting these properties, a number of fluorescent probes were reported for sensing thiols [43-46]. Among these probes, 2,4-dinitrobenzenesulfonyl (DNPS) and 2,4-dinitrophenyl (DNP) are two commonly used recognition moieties, which can act as favored sites for nucleophilic attack by thiols [47-50]. Compared with biothiols, such as glutathione (GSH), cysteine (Cys), and homocysteine (Hcy), $\mathrm{PhSH}$ has a higher $\mathrm{pK}_{\mathrm{a}}$ value (ca. $6.5 \mathrm{for} \mathrm{PhSH}$ and ca. 8.5 for biothiols); thus, it mostly (about 98\%) exists as the anionic $\mathrm{PhS}^{-}$under neutral physiological conditions 
$(\mathrm{pH}=7.4)$ while biothiols remain as the neutral form (RSH). Consequently, $\mathrm{PhSH}$ can act as a more powerful nucleophile compared with biothiols. On the basis of the different reactivities, a number of selective PhSH probes were obtained by incorporating the DNPS or DNP moiety into various screened fluorophores. Although rapid progress was achieved in recent years in developing fluorescent assays for sensing PhSH based on synthetic fluorescent probes, these studies are yet to be comprehensively addressed. In this review, the reports of fluorescent $\mathrm{PhSH}$ probes (including several colorimetric and luminescent probes) are systematically summarized and classified according to recognition moieties. Prospects for future research are discussed as well.

\section{Probes Based on 2,4-Dinitrobenzenesulfonic Amide}

Wang et. al. reported the first fluorescent probe (1) for the selective detection of $\mathrm{PhSH}$ [51]. The probe was obtained by incorporating DNBS into an NBD (7-nitro-2,1,3-benzoxadiazole) fluorophore (Figure 1). Due to the blockage of the ICT (intramolecular charge transfer) process and the quenching effects of the DNBS moiety, probe $\mathbf{1}$ was non-fluorescent. In an aqueous buffer solution, probe $\mathbf{1}$ can display a fast turn-on fluorescence response due to the effective cleavage of the sulfonamide by $\mathrm{PhSH}$ via an $\mathrm{S}_{\mathrm{N}} \mathrm{Ar}$ (nucleophilic aromatic substitution) process and, thus, release the free fluorophore NBD-NH ${ }_{2}$. Notably, the probe demonstrates excellent selectivity over aliphatic thiols and other common nucleophiles. Considering the relatively low quantum yield $(\Phi=0.02)$ and low sensitivity (limit of detection, $\mathrm{LOD}=2 \mu \mathrm{M}$ ) of the probe 1 system, the same research group subsequently developed a novel PET (photoinduced electron transfer)-based fluorescent probe (2) for sensing $\mathrm{PhSH}$ [52], which displayed a much higher quantum yield $(\Phi=0.39$; quantum yield was determined by reference to harmine in $0.1 \mathrm{~N} \mathrm{H}_{2} \mathrm{SO}_{4}\left(\Phi^{\prime}=0.45\right)$ ) and a higher sensitivity (LOD $\left.=0.2 \mu \mathrm{M}\right)$. Probe 2 also displayed excellent specificity and can work in a phosphate buffer under physiological conditions (pH 7.3, $0.01 \mathrm{M})$.
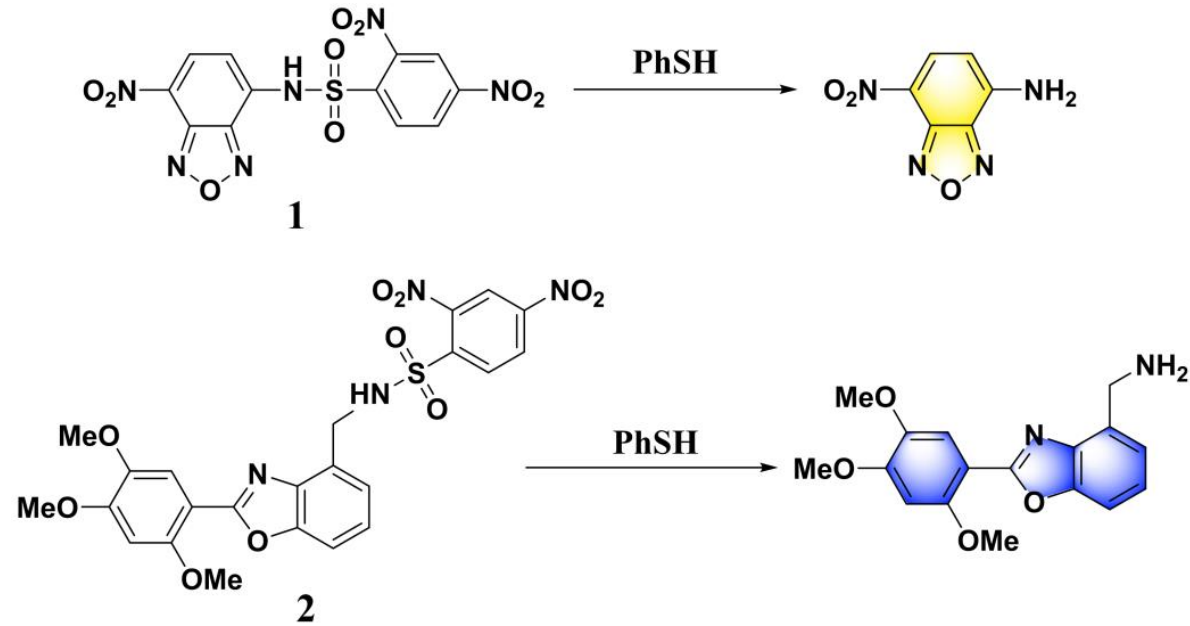

Figure 1. Structures and reactions of probes $\mathbf{1}$ and $\mathbf{2}$ with thiophenol $(\mathrm{PhSH})$.

Since the pioneering works by Wang and co-workers, considerable efforts were expended for the development of efficient fluorescent $\mathrm{PhSH}$ probes. By appending DNBS to a naphthalimide-derived fluorophore, Han and Deng et al. designed a reaction-based fluorescent, probe (3) (Figure 2) for $\mathrm{PhSH}$ [53]. Probe 3 was shown to be selective and sensitive (LOD $=20 \mathrm{nM}$ ), which was presumably ascribed to the suitable electronic structure and spectroscopic property of the probe, benefiting from the linker moiety of 2,3-dihydroimidazo-[1,2-a] pyridine. In the presence of $\mathrm{PhSH}$ (ca. 2.0 equivalents), the probe solution showed a remarkable turn-on fluorescent response ( $>60$-fold) with a fluorescence quantum yield of 0.36. Furthermore, probe 3 was used successfully for monitoring PhSH in water samples from rivers and chemical factories; the feasibility of the proposed assay was also validated using the traditional GC-FPD (gas chromatography-flame photometric detector) method. 


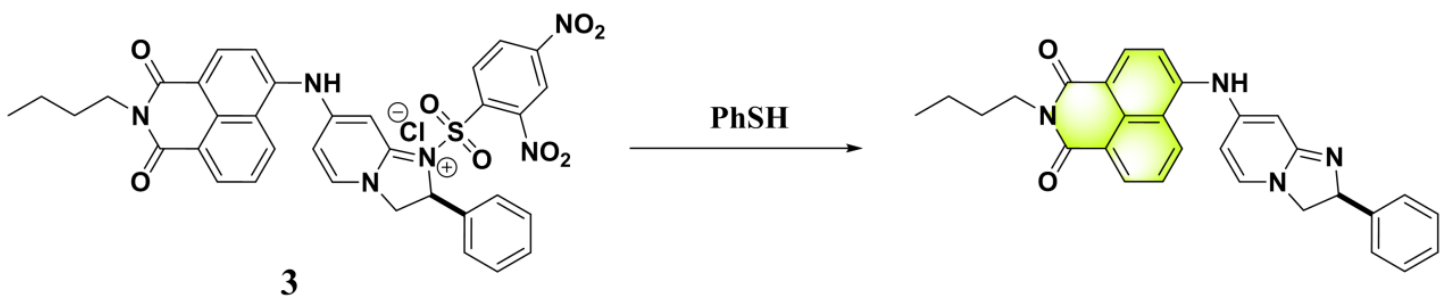

Figure 2. Structure and reaction of probe 3 with $\mathrm{PhSH}$.

By adopting coumarin-3-amino as the fluorophore, Yang et al. developed a fluorescent $\mathrm{PhSH}$ probe (4) (Figure 3) [54]. In a phosphate buffer solution, probe 4 displayed a significant fluorescence enhancement (>280-fold) with a large Stokes shift $(145 \mathrm{~nm})$ for sensing PhSH. Probe 4 also exhibited excellent selectivity for PhSH over relevant aliphatic thiols. Thus, the probe was directly applied to detection $\mathrm{PhSH}$ in real water samples, which produced good recovery results, indicating that probe 4 can serve as a promising tool for sensing thiophenol in the environmental field. To further improve the analytical performances of the coumarin-based fluorescent probe, the same research group designed a new probe (5) for PhSH via a twist-blockage strategy [55]. The benzo[ij]quinolizine coumarin-based probe (5) exhibited more advantageous features, including higher fluorescence enhancement $(700$-fold) and sensitivity ( $\mathrm{LOD}=4.5 \mathrm{nM})$. Probe 5 was also employed for imaging exogenous PhSH in HEK293 cells.

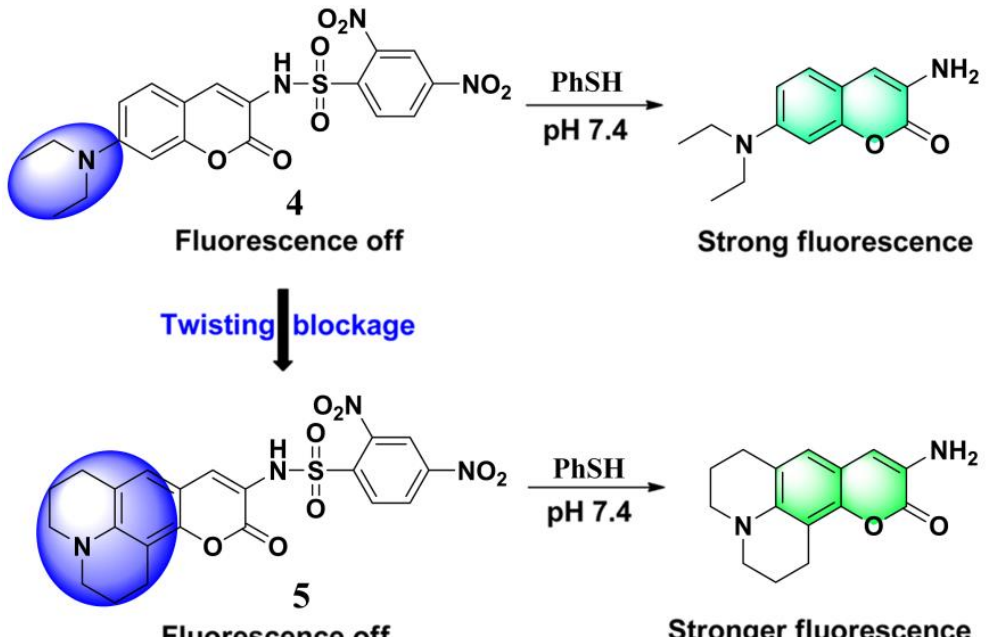

Fluorescence off

Stronger fluorescence

Figure 3. Structures and reactions of probes 4 and 5 with PhSH. Reproduced with permission from References [54,55]; copyright American Chemical Society.

Boron dipyrromethene difluoride (BODIPY)-based dyes have several advantages such as a high molar extinction coefficient and fluorescence quantum yield, excellent photostability, and narrow emission bands [56-59]. Talukdar et al. reported a BODIPY-based probe (6) (Figure 4) for fluorescence turn-on detection of $\mathrm{PhSH}$ [60]. The fluorescence off-on process was confirmed by theoretical calculations. Probe 6 displayed a forbidden $\mathrm{S}_{0} / \mathrm{S}_{1}$ transition (oscillator strength, $f=0.0561$ ), while the presumed reaction product of 6 with PhSH allowed the $S_{0} / S_{1}$ transition $(f=0.4693)$ (Figure $6 c$ ). In phosphate buffer (containing $1 \%$ dimethyl sulfoxide (DMSO), $\mathrm{pH} 7.3$ ), the fluorescence intensity of the probe 6 system was found to increase linearly with PhSH concentration. The dynamic range was 2-10 $\mu \mathrm{M}$ with an LOD of $34.4 \mathrm{nM}$. By employing an extended $\pi$-conjugated BODIPY dye, Zhang and Zhao et al. developed a long-wavelength PhSH probe (7) (Figure 4) with the emission band located around $640 \mathrm{~nm}$ [61]. Based on an amino phenothiazine boranil dye, Chen and Sheng et al. developed a highly sensitive fluorescent probe (8) (Figure 4) for sensing PhSH [62]. Recently, Thilagar et al. 
synthesized two triarylborane-derived fluorescent $\mathrm{PhSH}$ probes (9 and 10) (Figure 4), which displayed high sensitivity and selectivity, as well as applicability for intracellular imaging [63].
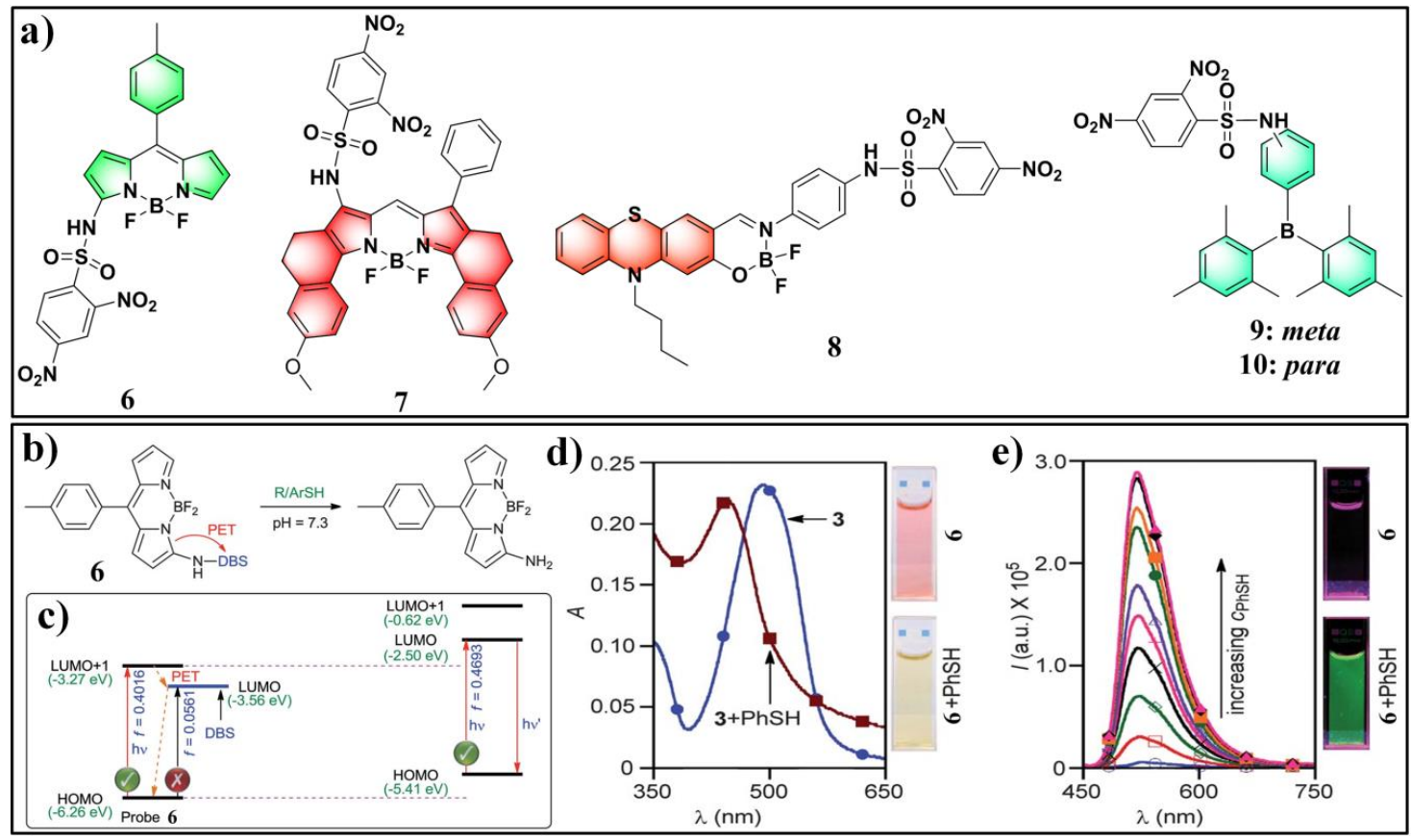

Figure 4. (a) Fluorescent PhSH probes (6-10) based on boron-containing dyes. (b) Reaction of probe 6 with PhSH. (c) Energy level diagram of the frontier molecular orbitals (MOs) of probe 6 and corresponding amine. (d) Ultraviolet-visible light (UV-Vis) absorption spectra of probe $\mathbf{6}$ before and after addition of $\mathrm{PhSH}$; photographs were taken under ambient light. (e) Fluorescence spectra of 6 in the presence of different concentrations of PhSH. Photographs taken under a hand-held UV lamp. Reproduced with permission from Reference [60]; copyright Royal Society of Chemistry.

Luminescent heavy-metal complexes showed some favorable photophysical characteristics for sensing and bioimaging applications, such as a large Stokes shift and long emission lifetime, which are very helpful for eliminating autofluorescence in complicated biological and environmental samples [64-70]. Lu et al. presented a cyclometalated iridium-based phosphorescent probe (11) (Figure 5) for sensing PhSH [71]. Probe 11 is almost non-fluorescent due to the PET quenching process. PhSH can trigger a distinct turn-on photoluminescence for the probe system. The photoluminescence lifetimes were determined to be $1.99 \mu$ s for de-aerated and $0.50 \mu$ s for aerated samples. The photoluminescence response was also very sensitive $\left(k=91.92 \times 10^{6} \mathrm{M}^{-1}\right)$ with a determined LOD of $2.5 \mathrm{nM}$. Recently, Zhang and Pu et al. reported another cyclometalated iridium(III) complex (12) (Figure 5) for detecting $\mathrm{PhSH}$ [72]. 


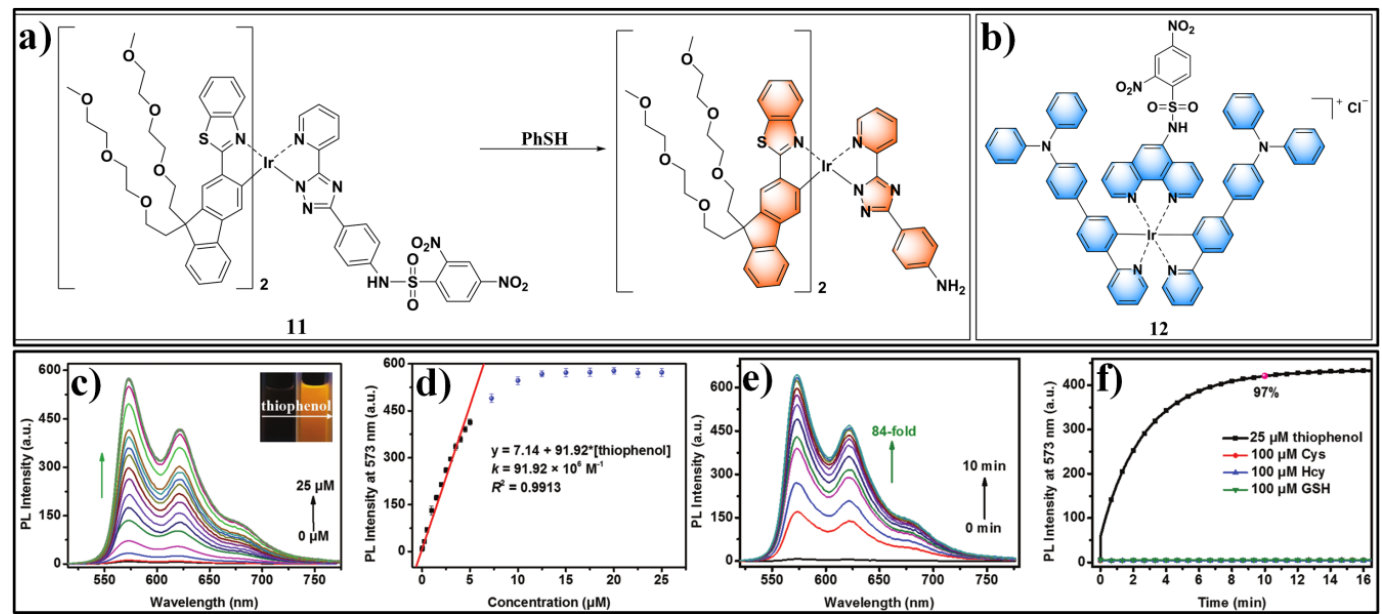

Figure 5. (a) Structure and reaction of probe 11 with $\mathrm{PhSH}$. (b) Structure of probe 12. (c) Phosphorescence spectra of probe $\mathbf{1 1}$ in the presence of different concentrations of thiophenol. (d) The correlation between phosphorescence intensity of probe $\mathbf{1 1}$ at $573 \mathrm{~nm}$ and concentration of thiophenol. (e) Phosphorescence spectra of probe $\mathbf{1 1}$ in the presence of thiophenol at different reaction times. (f) Fluorescence enhancement profile of phosphorescence intensity at $573 \mathrm{~nm}$ of probe $\mathbf{1 1}$ in the presence of thiophenol (five equivalents) or thiol species (20 equivalents) under nitrogen conditions. Reproduced with permission from Reference [71]; copyright Royal Society of Chemistry.

Near-infrared (NIR) fluorescent probes attracted great attention due to their better capability for deep tissue penetration and reducing phototoxicity [73-75]. Up to now, several near-infrared probes based on the recognition unit of 2,4-dinitrobenzenesulfonic amide were reported for sensing $\mathrm{PhSH}$. Based on a dicyanomethylene-benzopyran-derived dye, Feng et al. developed an NIR fluorescent probe (13) (Figure 6a) for sensing and imaging PhSH [76]. Upon addition of $\mathrm{PhSH}$, the probe buffer solution displayed a distinct turn-on NIR fluorescence around $670 \mathrm{~nm}$. The probe system showed large Stokes shift, high selectivity, and fast response time. The linear dynamic range was 1-10 $\mu \mathrm{M}$ with an LOD of $0.15 \mu \mathrm{M}$. Furthermore, probe 13 was demonstrated to be capable of imaging PhSH in living Hela cells (Figure 6b-e). Subsequently, three other NIR fluorescent PhSH probes (14 [77], 15 [78,79], and 16 [79]) emerged by adopting different fluorophores, including porphyrin, dicyanoisophorone, and Nile blue (Figure 7). By incorporating 2,4-dinitrobenzenesulfonic amide into other fluorophores, a number of fluorescent PhSH probes (17 [80], 18 [80], 19 [81], 20 [82], and 21 [83]) were also constructed (Figure 8).
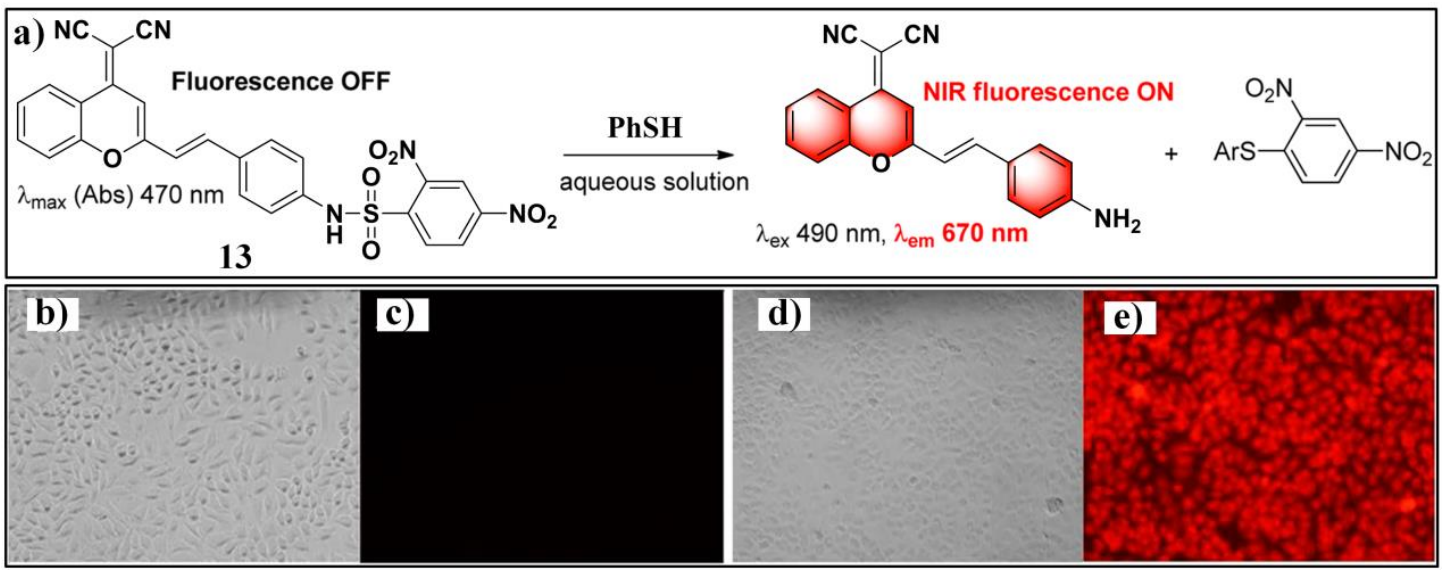

Figure 6. (a) Structure and reaction of probe 13 with PhSH. (b) Bright-field images of HeLa cells after being treated with probe 13. (d) HeLa cells preincubated with thiophenol and then incubated with probe 13. (c,e) Fluorescence images of $(\mathbf{b}, \mathbf{d})$, respectively. Reproduced with permission from Reference [76]; copyright American Chemical Society. 


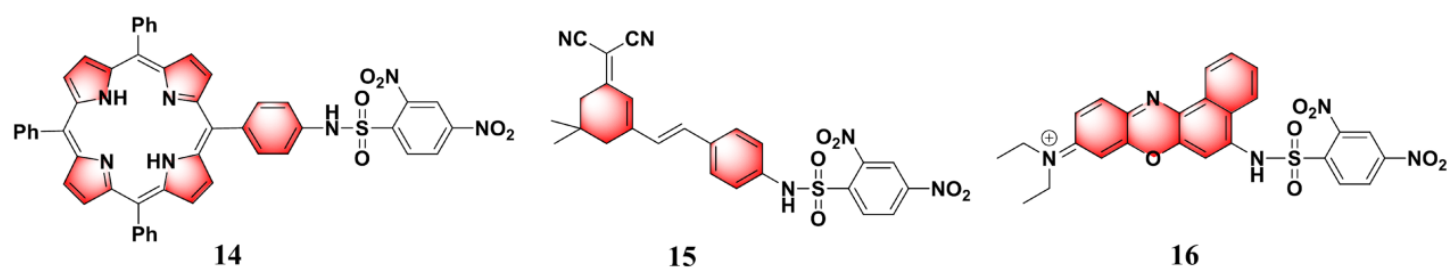

Figure 7. Other near-infrared (NIR) fluorescent PhSH probes (14-16) based on the recognition unit of 2,4-dinitrobenzenesulfonic amide.

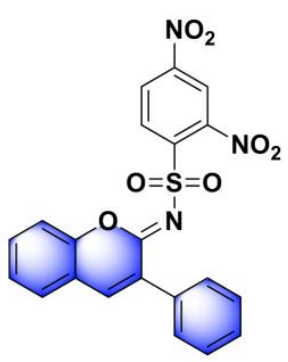

17

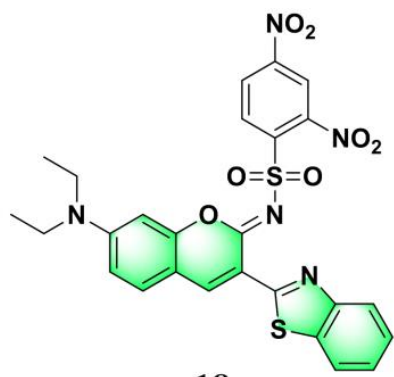

18

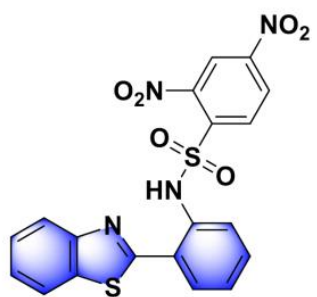

19
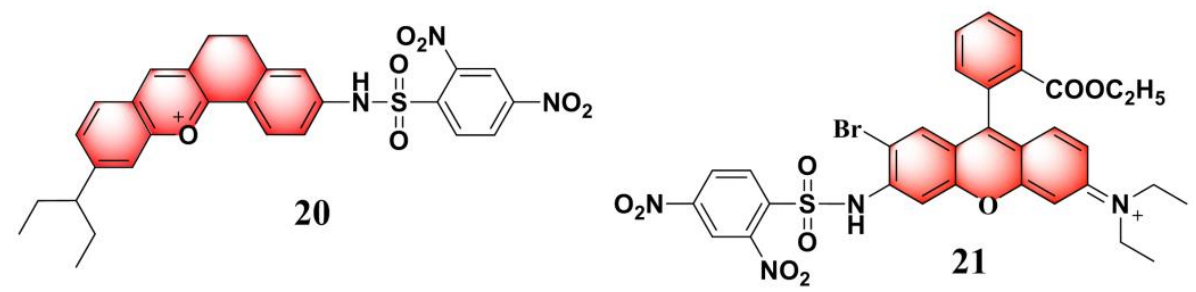

Figure 8. Fluorescent $\mathrm{PhSH}$ probes (17-21) based on the recognition unit of 2,4-dinitrobenzenesulfonic amide.

Recently, by introducing piperazine as a linker for connecting the fluorophore and the recognition moiety, a series of new fluorescent probes were developed for monitoring $\mathrm{PhSH}$. $\mathrm{Yu}$ and $\mathrm{Li}$ et al. reported a 1,8-naphthalimide-based fluorescent PhSH probe (22) (Figure 9) [84]. In a mixed solvent of water/ethanol $(7: 3, v / v)$, the probe displayed a turn-on fluorescence response toward $\mathrm{PhSH}$, which can be ascribed to target-induced cleavage of the 2,4-dinitrobenzenesulfonyl group and, thus, the release of the piperazine-appended 1,8-naphthalimide fluorophore. This sensing process was verified by NMR (nuclear magnetic resonance) and MS (mass spectroscopy) studies. Probe $\mathbf{2 2}$ was also shown to be very sensitive for $\mathrm{PhSH}$, as the LOD was determined to be $10.3 \mathrm{nM}$. Based on the similar designing strategy, several other fluorescent probes (23 [85], 24 [86], 25 [79], and 26 [87]) bearing a piperazine linker were also built for the detection of $\mathrm{PhSH}$ (Figure 10). Notably, probe 26, which was developed by He and Chen et al., consisted of two types of fluorophores (naphthalimide and dansyl) linked by the piperazine group. The dansyl group behaves not only as a recognition moiety but also as a signaling reporter. Probe 26 alone displayed a typical naphthalimide emission at $534 \mathrm{~nm}$, while a blue-shifted peak at $414 \mathrm{~nm}$ was gradually observed in the presence of $\mathrm{PhSH}$, which can be attributed to the release of the dansyl derivative. Thus, the ratiometric detection for $\mathrm{PhSH}$ was achieved.<smiles>Cc1ccccc1[N+](=O)[O-]</smiles>

22

Figure 9. Structure and reaction of probe 22 with $\mathrm{PhSH}$. 
<smiles>CC1=CC(=C(C#N)C#N)C=C(C=Cc2ccc(N3CCN(S(=O)(=O)c4ccc([N+](=O)[O-])cc4[N+](=O)[O-])CC3)cc2)O1</smiles>

23<smiles>CCCCN1C(=O)c2cccc3c(N4CCN(S(=O)(=O)c5ccc([N+](=O)[O-])cc5[N+](=O)[O-])CC4)ccc(c23)C1=O</smiles>

25
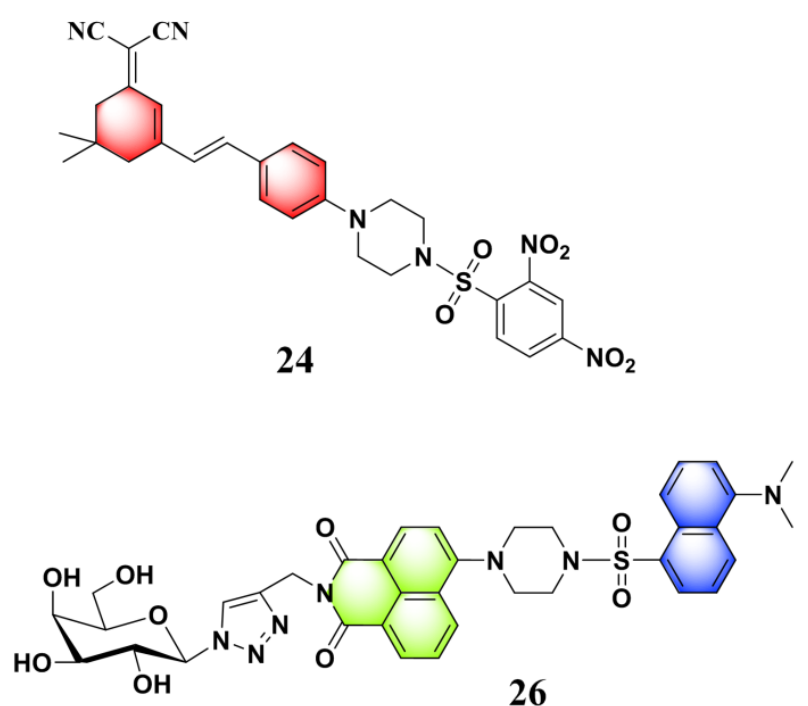

26

Figure 10. Fluorescent PhSH probes (23-26) containing the piperazine linker.

Photochromic molecules, which can perform a reversible phototransformation between two forms that have different absorption spectra, showed many promising applications in molecular switches, photonic devices, and sensors. Based on a photochromic diarylethene derivative, Cheng and Zhang et al. developed a colorimetric PhSH probe (27) (Figure 11) [88]. Probe 27, which was obtained by appending 2,4-dinitrobenzenesulfonyl groups to the bisthienylethene perfluordiarylethene, shows excellent reversible photochromic properties. It can be photoswitched between a colorless open form and a colored closed form upon irradiation with ultraviolet (UV) light/visible light. After reacting with $\mathrm{PhSH}$, the photochromism of the probe system can be effectively inhibited, with the photocyclization quantum yields $\left(\Phi_{\mathrm{o}-\mathrm{c}}\right)$ decreasing from 0.25 to 0.01 .

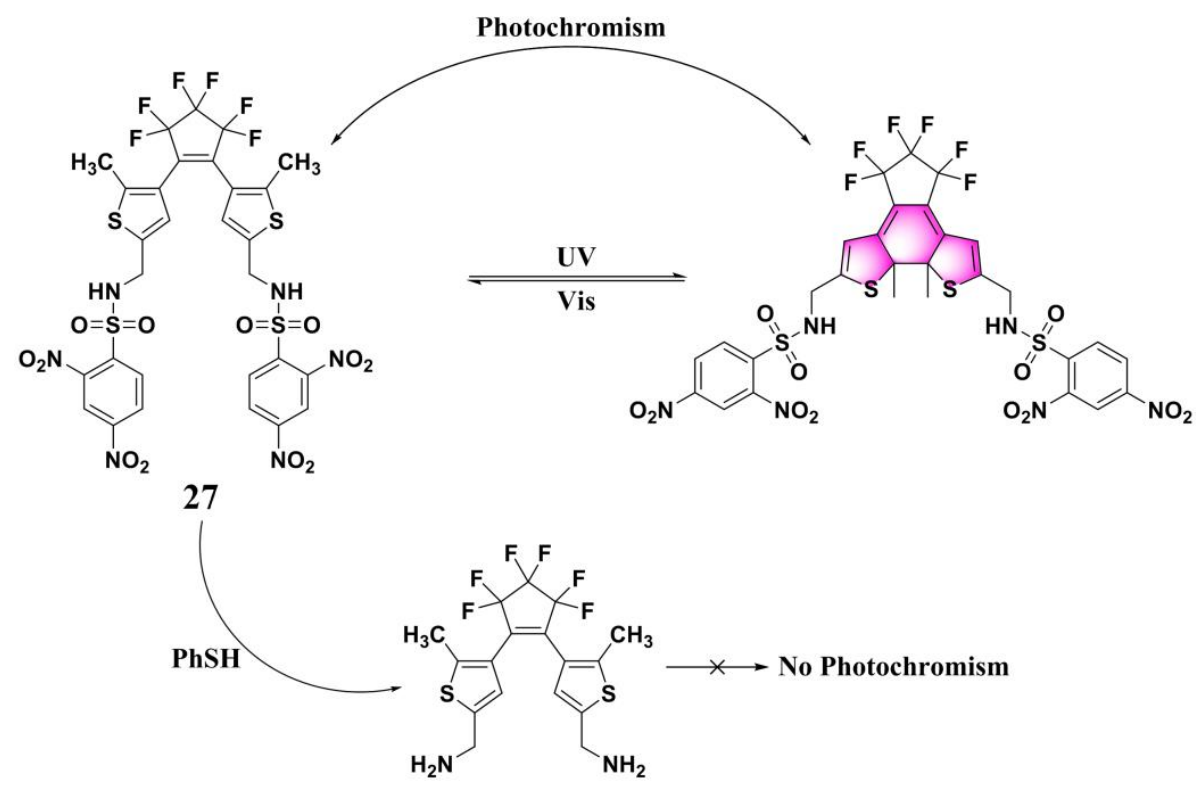

Figure 11. Structure and the sensing mechanism of probe 27 for $\mathrm{PhSH}$.

\section{Probes Based on 2,4-Dinitrobenzenesulfonate}

By using 2,4-dinitrobenzene-sulfonate as the recognition moiety, Zhang et al. reported the first two-photon fluorescent probe (28) (Figure 12) for PhSH detection [89]. The signal reporter of this probe is a TBET (through-bond energy transfer) system which was obtained by combining a donor 
of two-photon naphthalene with an acceptor of red-emissive BODIPY dye. The TBET fluorophore displayed a high energy transfer efficiency (93.5\%) from the donor to the acceptor. In the presence of $\mathrm{PhSH}$, the probe exhibited a high-sensitivity turn-on fluorescence response of the BODIPY acceptor at $586 \mathrm{~nm}$. The linear range of the $\mathrm{PhSH}$ was $0.05-2 \mu \mathrm{M}$, and the LOD corresponded to $4.9 \mathrm{nM}$. Furthermore, probe $\mathbf{2 8}$ was utilized for thymidine phosphorylase (TP) bioimaging PhSH in Hela cells, as well as in rat liver tissue slices.

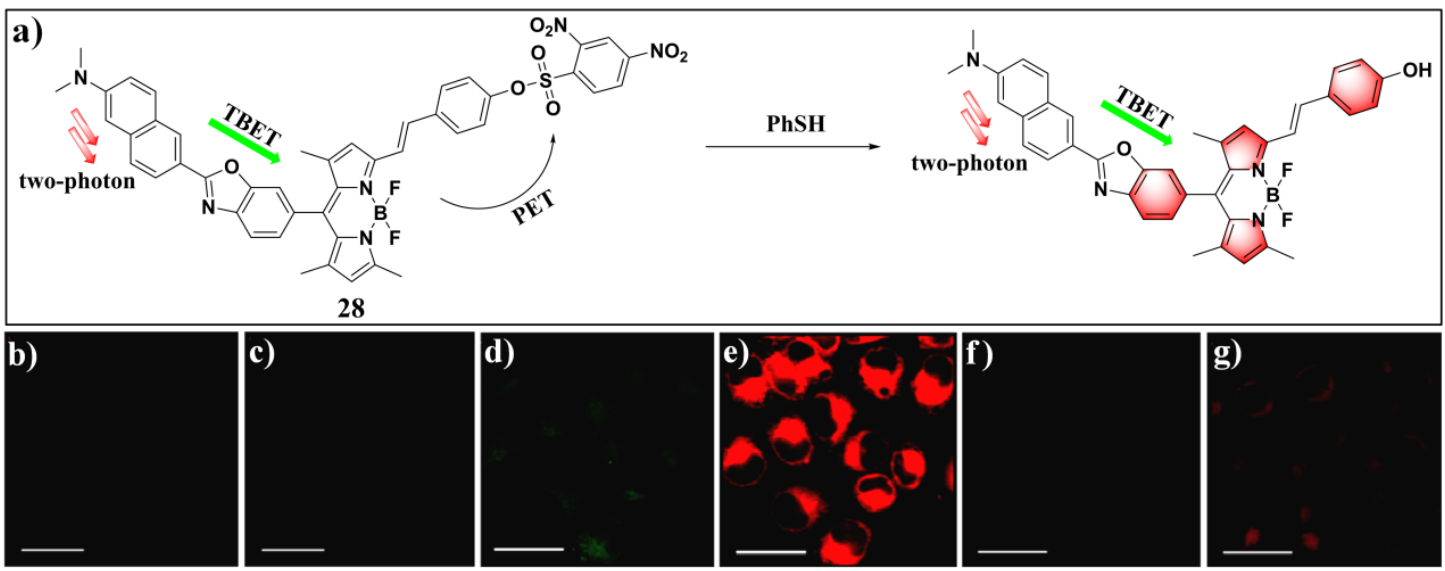

Figure 12. (a) Structure and reaction of probe 28 with PhSH. (b,d,f) Thymidine phosphorylase (TP) images of probe 28 in Hela cells from the green channel without thiophenol, with thiophenol, and with both NEM (N-ethylmaleimide) and thiophenol, respectively. (c,e,g) are corresponding TP images of $(\mathbf{b}, \mathbf{d}, \mathbf{f})$ from the red channel, respectively. Reproduced with permissions from [89]. Copyright American Chemical Society.

Squaraines, which possess a donor-acceptor-donor (D-A-D') and resonance-stabilized zwitterionic structure, exhibited several unique photophysical features for the construction of fluorescent probes, such as narrow and strong absorption and emission bands in the red to NIR region, excellent photostability, and tunable fluorescence emission properties [90-92]. Based on an arylidene-squaraine fluorophore, Lu et al. developed a far-red/near-infrared fluorescent probe (29) (Figure 13) for sensing $\mathrm{PhSH}$ [93]. Probe 29 exhibited both a sensitive colorimetric response (from pink to blue) and a fluorogenic response toward $\mathrm{PhSH}$. Due to the desirable electronic and spatial structures of the employed donating building blocks (D: benzindolylmethylene group and D': 2,4,6-trihydroxyphenyl group) connected to the squaraine core, the cyclobutene ring displayed good stability against nucleophilic attack by biothiols, such as GSH and Cys. Thus, the probe exhibited good selectivity. The probe was also very sensitive toward $\mathrm{PhSH}$; the dynamic range and LOD were $0-5 \mu \mathrm{M}$ and $9.9 \mathrm{nM}$, respectively.
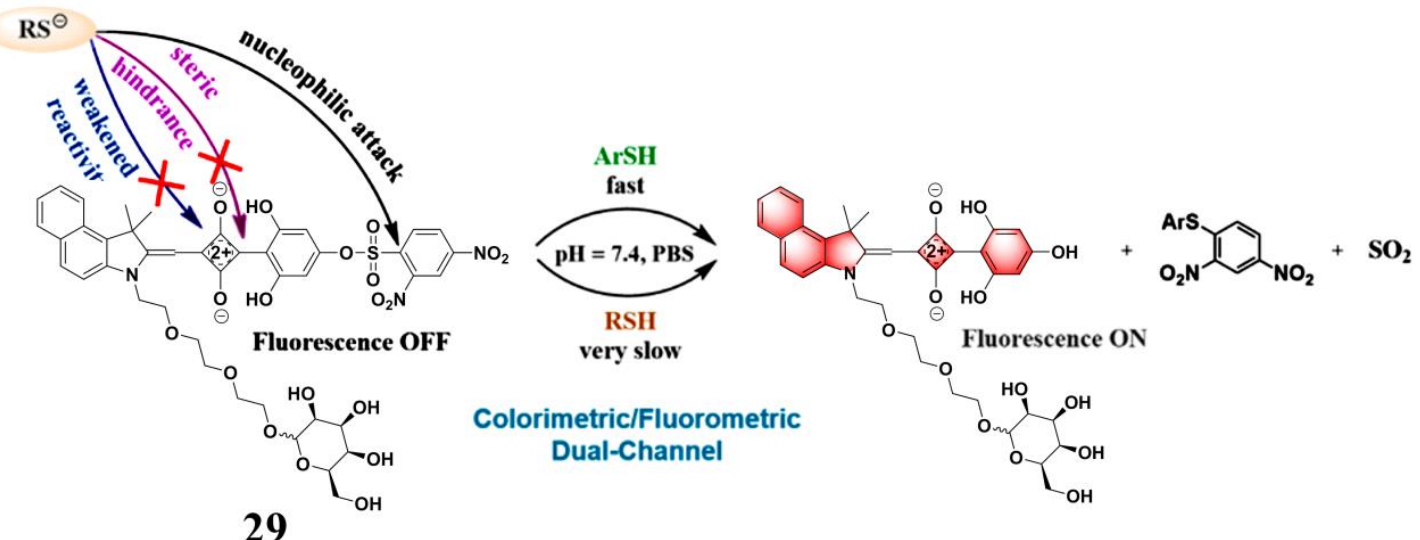

Figure 13. Structure and reaction of probe 29 with $\mathrm{PhSH}$. Reproduced with permission from Reference [93]; copyright American Chemical Society. 
By incorporating 2,4-dinitrobenzene-sulfonate into an aldehyded dicyanomethylene-benzopyranderived dye, Li et al. constructed near-infrared probe (30) (Figure 14) for colorimetric and fluorogenic detection of $\mathrm{PhSH}$ [94]. With the addition of $\mathrm{PhSH}$ to a phosphate buffer/DMSO $(v / v, 1: 1, \mathrm{pH}=7.4)$ solution of probe $\mathbf{3 0}$, the probe solution displayed a distinct color change from yellow to red with the evolution of a fluorescence emission at $658 \mathrm{~nm}$. The probe displayed excellent selectivity for $\mathrm{PhSH}$ amongst a selection of nucleophiles, including aniline, Cys, Hcy, and GSH. The LOD was calculated to be $0.22 \mu \mathrm{M}$. The probe was also employed for sensing $\mathrm{PhSH}$ in tap water and in river water samples, as well as imaging the target in living Hela cells.

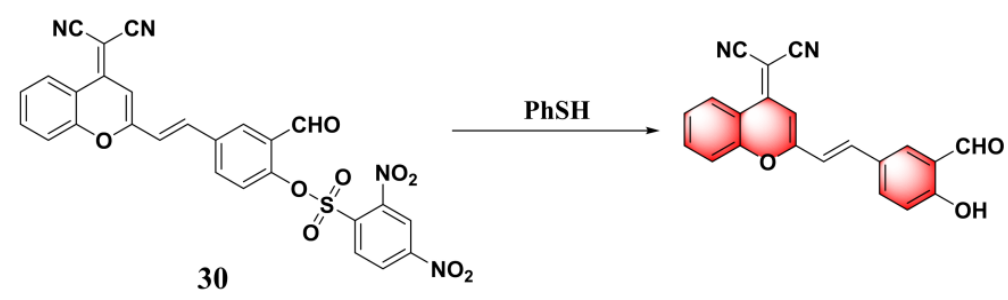

Figure 14. Structure and reaction of probe 30 with $\mathrm{PhSH}$.

By exploiting natural curcumin as the fluorophore, Martínez-Máñez and Yin et al. developed a turn-on fluorescent PhSH probe (31) (Figure 15) [95]. In a mixed solvent of HEPES (N-2-hydroxyethylpiperazine- $N$-2'-ethanesulfonic acid)-MeOH (methanol) $(1: 1, v / v, \mathrm{pH}=7.4), \mathrm{PhSH}$ can rapidly react with probe $\mathbf{3 1}$ and produce a significant fluorescence enhancement (20-fold) at around $536 \mathrm{~nm}$. The reaction was complete within dozens of seconds. The probe was also used for detection of PhSH in HepG2 cells. Combining 2,4-dinitrobenzene-sulfonate with various other fluorophores, including coumarin, benzoxazinone, naphthalene, and BODIPY, further yielded a number of fluorescent PhSH probes (31 [95], 32 [96], 33 [97], 34 [98], 35 [99], 36 [100], 37 [101], 38 [102], and 39 [103]) (Figure 15).<smiles>COc1cc(/C=C/C(=O)/C=C(O)/C=C/c2ccc(OS(=O)(=O)c3ccc([N+](=O)[O-])cc3[N+](=O)[O-])c(OC)c2)ccc1OS(=O)(=O)c1ccc([N+](=O)[O-])cc1N</smiles>
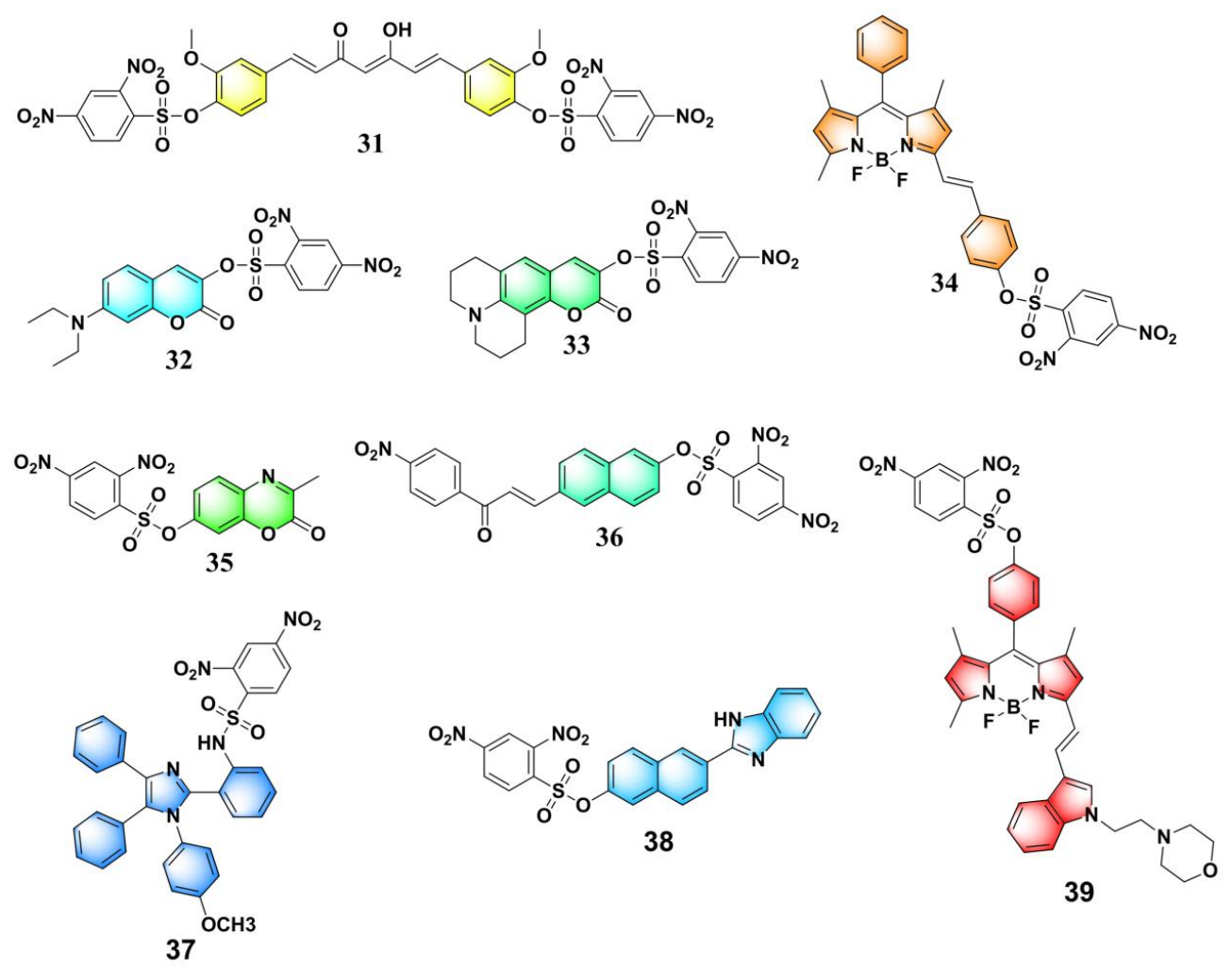

Figure 15. Fluorescent PhSH probes (31-39) based on the recognition unit of 2,4-dinitrobenzenesulfonate. 


\section{Probes Based on the Recognition Unit of 2,4-Dinitrophenyl Ether}

Lin et al. firstly proposed constructing a fluorescent $\mathrm{PhSH}$ probe (40) (Figure 16) by exploiting the target-induced thiolysis of a dinitrophenyl ether moiety [104]. The probe (40) was obtained by coupling a dinitrophenyl group to a 7-hydroxy coumarin. In a solution of phosphate buffer/DMF ( $N, N$-dimethylformamide) $(55: 45, v / v, 25 \mathrm{mM}, \mathrm{pH}=7.0)$, the probe is almost non-fluorescent $(\Phi=0.006)$, while PhSH can effectively mediate thiolysis of dinitrophenyl ether and result in the release of the highly emissive coumarin fluorophore $(\Phi=0.5)$. The quantum yield was calculated using the equation of $\Phi_{\mathrm{s}}=\Phi_{\mathrm{r}}\left(\mathrm{A}_{\mathrm{r}} \mathrm{F}_{\mathrm{s}} / \mathrm{A}_{\mathrm{s}} \mathrm{F}_{\mathrm{r}}\right)\left(\mathrm{n}_{\mathrm{s}} / \mathrm{n}_{\mathrm{r}}\right)^{2}$, where $\mathrm{A}_{\mathrm{s}}$ and $\mathrm{A}_{\mathrm{r}}$ are the absorbance of the sample and the reference at the excitation wavelength, respectively, $F_{S}$ and $F_{r}$ are the corresponding relative integrated fluorescence intensities, $\mathrm{n}$ is the refractive index of the solvent, and $\Phi_{\mathrm{S}}$ and $\Phi_{\mathrm{r}}$ are the quantum yields of the sample and the reference, respectively; quinine sulfate $\left(\Phi_{\mathrm{r}}=0.546\right.$ in $\left.1 \mathrm{~N} \mathrm{H}_{2} \mathrm{SO}_{4}\right)$ was used as the reference. The kinetic results indicated that the probe can react rapidly with the target. The spectral response of the probe solution was found to be very sensitive toward PhSH. A linear dynamic range of $4.0 \mathrm{nM}-3.0 \mu \mathrm{M}$ was obtained between the logarithm of $\left(\left(I-I_{0}\right) / I_{0}\right)$, and the LOD was calculated to be $1.8 \mathrm{nM}$. Moreover, the probe was used for the first time to monitor PhSH in environmental and biological samples.

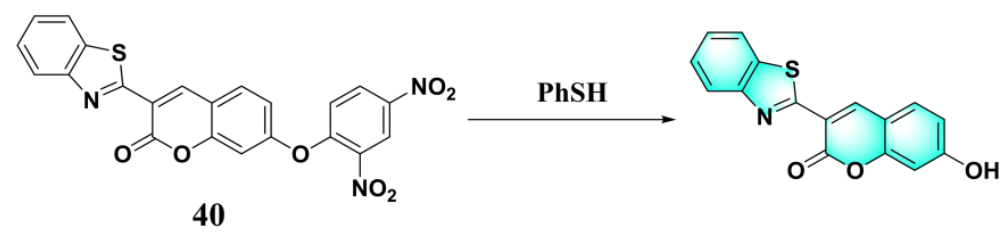

Figure 16. Structure and reaction of probe 40 with $\mathrm{PhSH}$.

Compared with the intensity-dependent single-band emission probe, the ratiometric fluorescent probe, which relies on the change in the ratio of two emission bands, is more attractive due to its potential capability to eliminate the influence of probe distribution and instrumental difference. The fluorescence resonance energy transfer (FRET) system, which consists of two dyes (donor and acceptor), is a commonly used platform for constructing ratiometric fluorescent assays [105-108]. Feng et al. developed a FRET-based ratiometric PhSH probe (41) (Figure 17) by using a pair of fluorophores, coumarin and naphthalimide [109]. As the fluorescence of the naphthalimide acceptor was quenched by dinitrophenyl ether, probe 41 alone displayed the typical emission $\left(\lambda_{\mathrm{em}}=481 \mathrm{~nm}\right)$ of the coumarin donor. PhSH can selectively remove the dinitrophenyl ether and trigger the occurrence of the FRET process, thus achieving a good ratiometric fluorescent response.

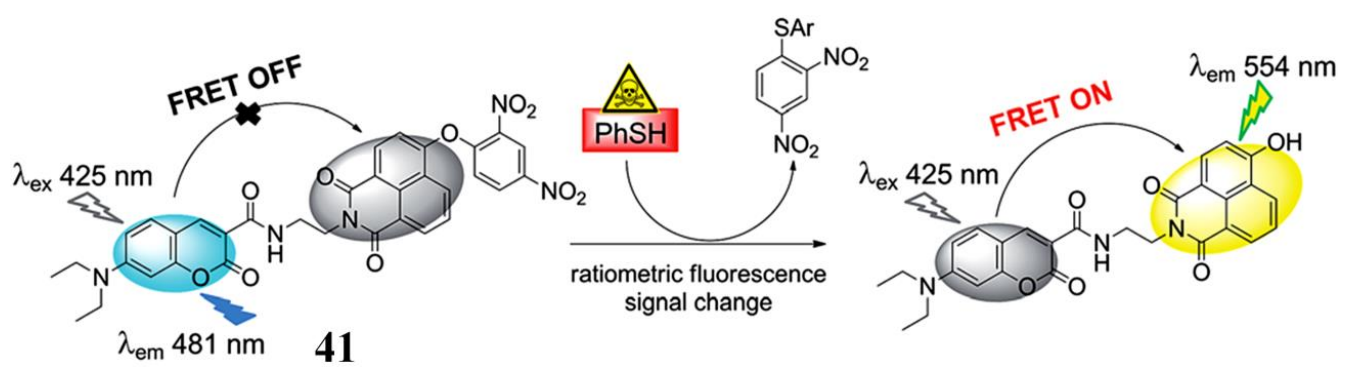

Figure 17. Structure and reaction of probe $\mathbf{4 1}$ with $\mathrm{PhSH}$. Reproduced with permission from Reference [109]; copyright Royal Society of Chemistry.

Based on the strategy of target-induced in situ formation of a red-emissive coumarin fluorophore, Song et al. reported a reaction-based turn-on fluorescent probe (42) (Figure 18) for sensing PhSH [110]. Firstly, the probe underwent a target-mediated cleavage of the dinitrophenyl ether moiety in the presence of PhSH. Then, the liberated phenolic oxygen could subsequently perform an intramolecular nucleophilic attack on the nitrile group, leading to the generation of the cyclized iminocoumarin scaffold acting as the signal reporter. The sensing process was further verified by HPLC (high-performance 
liquid chromatography), NMR, and MS analysis. The probe also displayed a very fast reaction rate (within $120 \mathrm{~s}$ ) for response to PhSH. Exploiting a similar sensing strategy, Chen and Sheng et al. consequently reported a phenothiazine-coumarin-based red-emitting probe (43) for detection of $\mathrm{PhSH}$ [111]. In aqueous solution, the formed imino group via PhSH-induced cleavage and an intramolecular cyclization process could further be converted to oxygen via a hydrolysis reaction. Probe 43 exhibited an unusually large Stokes shift $(140 \mathrm{~nm})$ and a high sensitivity $(\mathrm{LOD}=2.9 \mathrm{nM})$ for sensing PhSH.
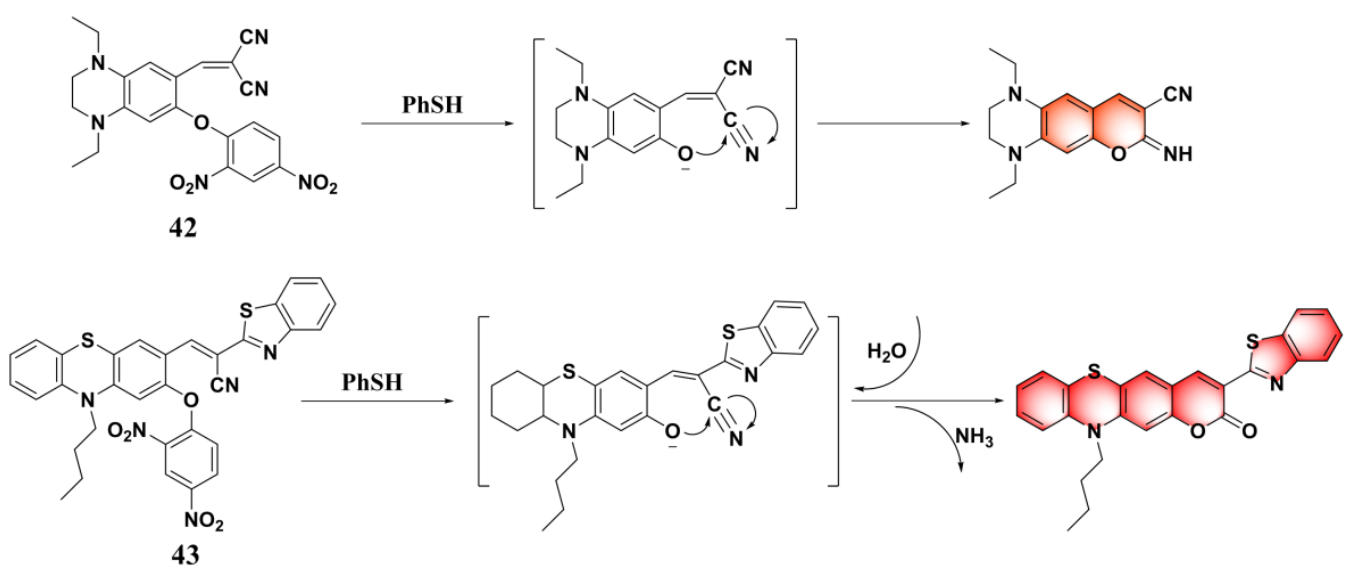

Figure 18. Structures and sensing mechanisms of probes $\mathbf{4 2 - 4 3}$ for $\mathrm{PhSH}$

By integrating different fluorophores and reaction sites into a single molecular probe, Song et al. established a potent sensing platform (probe 44) for differentiating various thiols (including Cys/Hcy, $\mathrm{GSH} / \mathrm{H}_{2} \mathrm{~S}$, and thiophenol) [112]. Probe 44 incorporated three latent fluorometric fluorophores, blue-emitting coumarin, green-emitting NBD, and a red-emitting coumarin analogue. As shown in Figure 19a, Cys/Hcy, GSH/ $\mathrm{H}_{2} \mathrm{~S}$, and thiophenol can generate different combinations of fluorescence signals, corresponding to blue-green, blue, and blue-red, respectively. Moreover, this probe system also can be utilized for discriminating these groups of thiols ( $\mathrm{Cys} / \mathrm{Hcy}, \mathrm{GSH} / \mathrm{H}_{2} \mathrm{~S}$, and thiophenol) in living cells via recording fluorescence signals in different spectral channels (Figure 19b).

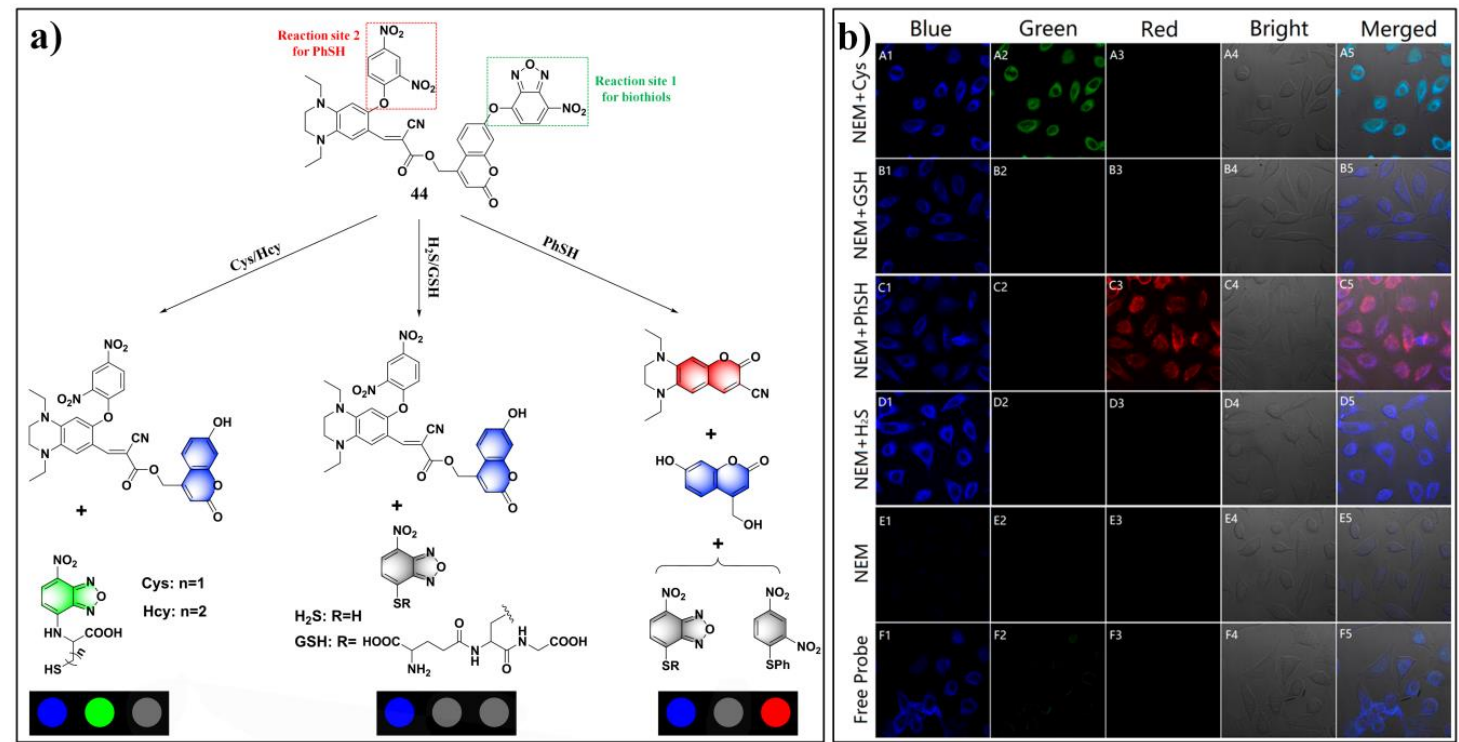

Figure 19. (a) Schematic illustration of the sensing mechanism of probe 44 for differentiating cysteine (Cys)/homocysteine (Hcy), glutathione (GSH)/ $\mathrm{H}_{2} \mathrm{~S}$, and thiophenol. (b) Images of Hela cells incubated with different regents. Reproduced with permission from Reference [112]; copyright American Chemical Society. 
Excited-state intramolecular proton transfer (ESIPT)-based fluorescent probes are highly attractive due to their unique optical features, such as large Stokes shift, high fluorescence quantum yield, tunable structure and emission wavelength, and potential for ratiometric sensing [8,113]. By coupling 2,4-dinitrophenyl ether to a green-emissive ESIPT fluorophore, 3-hydroxyphthalimide, Song et al. synthesized a turn-on fluorescent PhSH probe (45) (Figure 20) [114]. Due to the PET process from the fluorophore to the dinitrophenyl ether moiety, probe 45 is non-fluorescent $\left(\Phi_{\mathrm{F}}<0.001\right)$. Upon addition of $\mathrm{PhSH}$, the dinitrophenyl ether group of the probe can be cleaved to liberate 3-hydroxyphthalimide which can undergo an ESIPT process under photoexcitation and exhibit the keto-form emission at $516 \mathrm{~nm}$. The probe system displayed a large Stokes shift (161 nm). The dynamic range and LOD for sensing PhSH are 0-10 $\mu \mathrm{M}$ and $3.5 \mathrm{nM}$, respectively. By using other ESIPT fluorophores, including 2-(2'-hydroxy-phenyl)benzothiazole (HBT), an imidazo [1,5- $\alpha$ ]pyridine derivative, and phenothiazine-HBT compound, three other fluorescent $\mathrm{PhSH}$ probes (46 [115,116], 47 [117], and 48 [118]) were also presented (Figure 20).
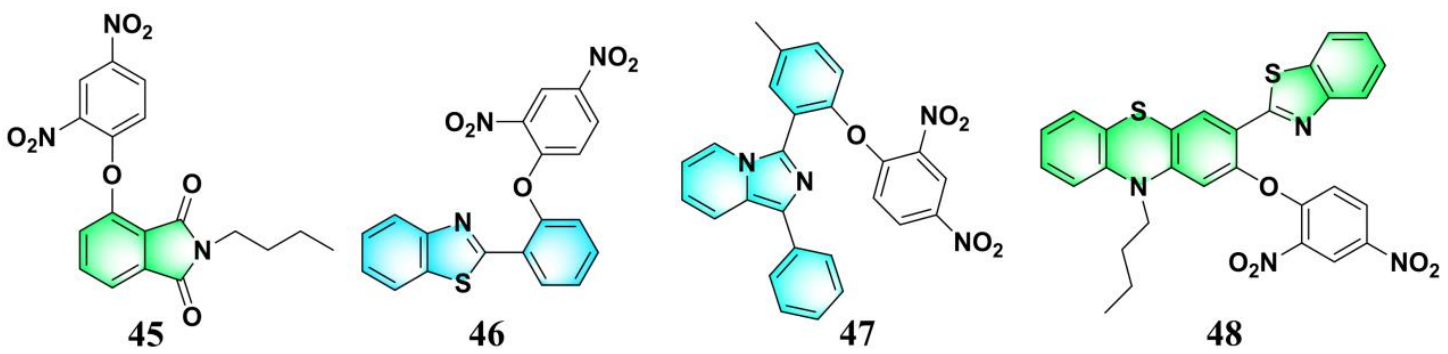

Figure 20. Fluorescent PhSH probes (45-48) based on excited-state intramolecular proton transfer (ESIPT) fluorophores.

Positively charged dyes showed great potential for the construction of fluorescent probes, due to their favorable electronic structures and optical properties, improved water solubility, and mitochondrial targeting ability [119-121]. By using 7-hydroxy quinolinium as the fluorophore, Song et al. developed an off-on fluorescent probe (49) (Figure 21) for sensing PhSH [122]. The probe can quickly respond to $\mathrm{PhSH}$ with a rate constant of $k=24 \mathrm{M}^{-1} \cdot \mathrm{s}^{-1}$. Studies on $\mathrm{pH}$ effects revealed that the probe can effectively react with $\mathrm{PhSH}$ under neutral physiological conditions. Liu and Song et al. reported a red-emissive fluorescent PhSH probe (50) (Figure 21) based on a methylated chromenoquinoline dye [123]. The probe system displayed a large Stokes shift $(108 \mathrm{~nm})$ and a high sensitivity (LOD = 8.1 nM) for sensing PhSH. Kinetic studies revealed that the reaction with probe $\mathbf{5 0}$ can be completed within $2 \mathrm{~min}$. The probe also showed excellent specificity for $\mathrm{PhSH}$ as other nucleophilic reagents (including Cys, $\mathrm{Hcy}, \mathrm{GSH}$, and HS$^{-}$) did not generate any fluorescence response. Guo et al. presented a mitochondrial-targeted fluorescent PhSH probe (51) (Figure 21) by using a rhodol-methylpyridinium derivative as the fluorophore [124]. Probe 51 can display both a distinct colorimetric and a fluorogenic response toward $\mathrm{PhSH}$ in a solvent of phosphate buffer ( $\mathrm{pH}=7.4,20 \mathrm{mM}$, containing 20\% DMF). Cellular co-localization experiments showed that the probe can stain mitochondria with a high coefficient (0.95) using Mito Tracker Green FM as the reference. The effects of endogenous reactive oxygen species (ROS) on the fluorescence response of probe 51 to $\mathrm{PhSH}$ in living cells were also inspected, which revealed that endogenous ROS could eliminate the fluorescence of the probe system. The results implied that thiophenols can participate in oxidative stress and redox regulation reactions. Zeng and Yuan et al. developed a selective NIR fluorescent probe (52) (Figure 21) for sensing and imaging PhSH by screening a library of seven fluorescent probes which were established by installing nitrobenzenesulfonyl or nitrophenyl groups onto NIR chromenylium-cyanine fluorophores [125]. The probe has both excitation and emission in the NIR region, corresponding to 680 and $706 \mathrm{~nm}$, respectively. In a phosphate buffer solution (25 mM, pH 7.4, containing 1\% DMSO), the emitted fluorescence intensity of probe 51 at $706 \mathrm{~nm}$ increased linearly with concentration of $\mathrm{PhSH}$ in a range of $1-15 \mu \mathrm{M}$ with an LOD of $280 \mathrm{nM}$. 
Furthermore, the probe exhibited excellent biocompatibility and cell-membrane permeability, and was successfully exploited for imaging PhSH in living HeLa cells, as well as in living mice.

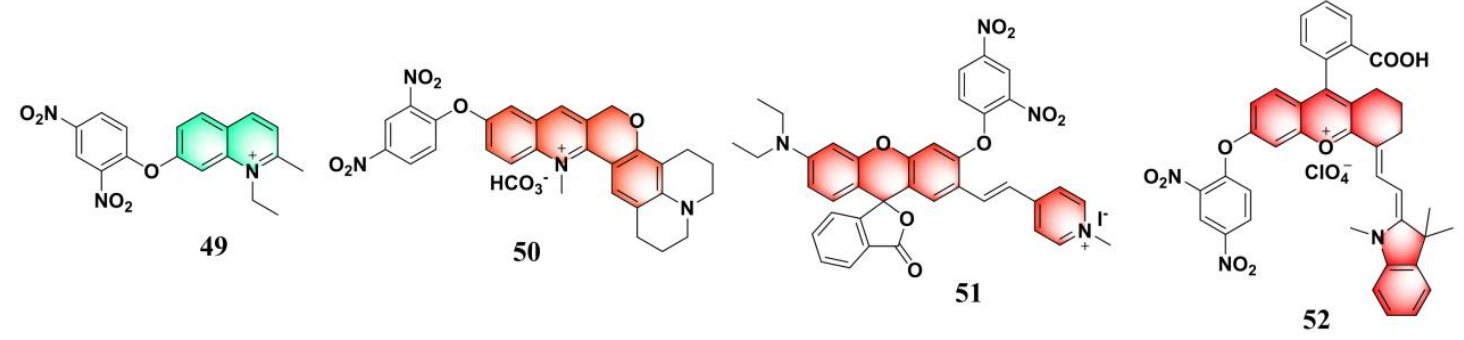

Figure 21. Fluorescent $\mathrm{PhSH}$ probes (49-52) based on positively charged fluorophores.

The emissive ruthenium complex is a promising luminescent material for sensing and imaging applications due to its unique photophysical properties, such as high molar extinction coefficient, high luminescent efficiency, large Stokes shift, long luminescence lifetime, and enhanced thermal and photo-chemical stabilities [126-130]. By utilizing 2,2'-bipyridine (bpy) and 4-(4-(2,4-dinitrophenoxy)phenyl)-2,2'-bipyridine (DNP-bpy) as ligands, Yuan et al. synthesized a series of Ru derivatives (53-55) (Figure 22a), $\left[\mathrm{Ru}(\mathrm{bpy})_{3-\mathrm{n}}(\mathrm{DNP}-\mathrm{bpy})_{\mathrm{n}}\right]\left(\mathrm{PF}_{6}\right)_{2}(\mathrm{n}=1,2,3)$, for luminescent sensing PhSH [131]. Due to the PET process from the luminescent Ru center to the 2,4-dinitrophenyl moiety, these probes are only weakly emissive. The luminescent behaviors of probes $\mathbf{5 3 - 5 5}$ and their responses toward PhSH were systematically studied. Among these probes, $\left[\mathrm{Ru}(\mathrm{bpy})(\mathrm{DNP}-\mathrm{bpy})_{2}\right]^{2+}$ (54) had the lowest quantum yield and displayed the most remarkable turn-on luminescent response to $\mathrm{PhSH}$. The results also demonstrate that the symmetry of the ligands is a critical factor influencing the luminescence features of the Ru-complex. In an aqueous buffer solution (20 mM HEPES, pH 7.0), probe 54 could sensitively respond to $\mathrm{PhSH}$ with a linear dynamic range of 1-12 $\mu \mathrm{M}$ and an LOD of $32.9 \mathrm{nM}$. Moreover, all these probes showed high specificity toward PhSH. Probe $\mathbf{5 4}$ can also be exploited for imaging exogenous PhSH in living cells (Figure 22b). Further cellular imaging experiments demonstrated that probe $\mathbf{5 4}$ has excellent intracellular retention, long-term stability to resist photobleaching, low cytotoxicity, and the tendency of nuclear localization.

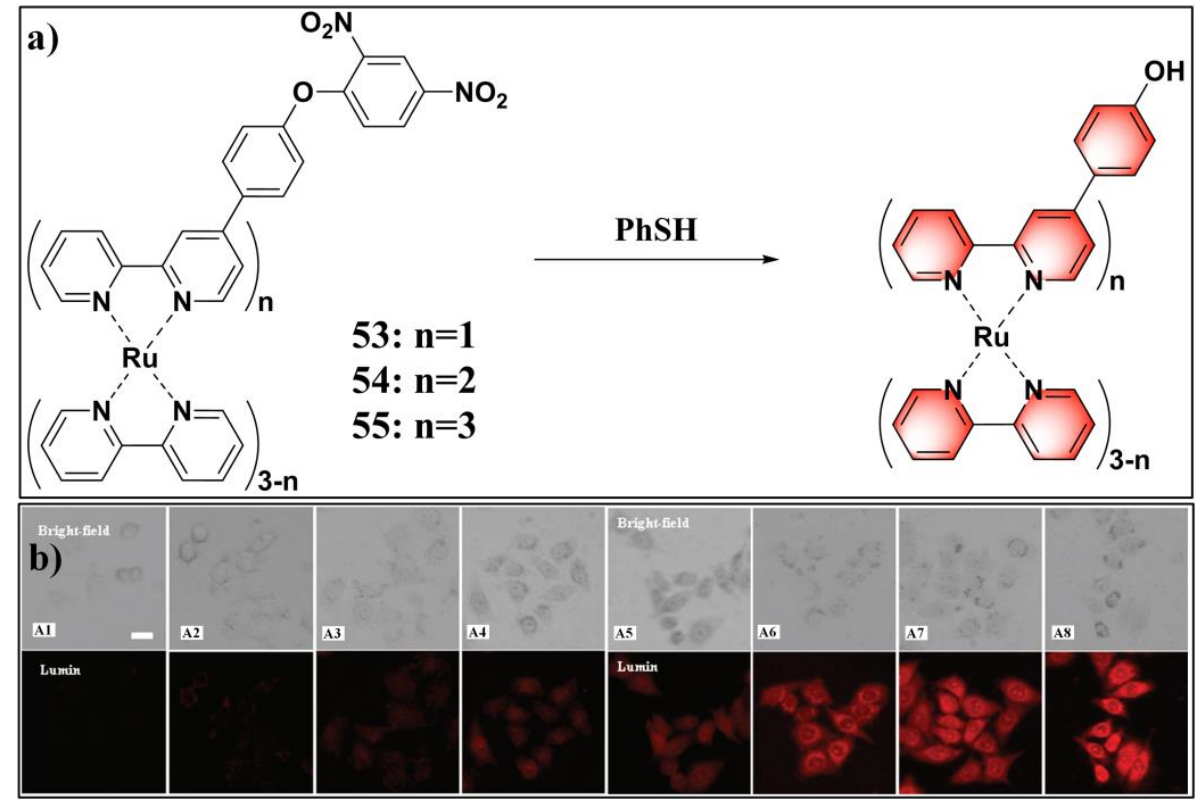

Figure 22. (a) Structure and reaction of probes 53-55 with PhSH. (b) Images of 54-loaded Hela cells incubated with PhSH for different times, from A1 to A8 (0, 5, 10, 20, 30, 40, 50, $60 \mathrm{~min})$; scale bar: $10 \mu \mathrm{m}$. Reproduced with permission from Reference [131]; copyright American Chemical Society. 
Chemiluminescence- and bioluminescence-based analytical assays have a number of advantages including simple procedures and equipment as no excitation light is needed, low background signal and high sensitivity, and good biocompatibility $[132,133]$. Li et al. reported a dual bioluminescent and chemiluminescent PhSH probe (56) (Figure 23) based on coelenterazine [134]. In Tris-HCl buffer (50 mM, pH 7.4) with the addition of luciferase, the probe system can be used for bioluminescent sensing of $\mathrm{PhSH}$ with an emission peak at $445 \mathrm{~nm}$. When replacing luciferase with dimethyl sulfoxide (DMSO), the probe system can act as a chemiluminescent sensor for PhSH with an emission peak at $522 \mathrm{~nm}$. Both of these luminescent assays displayed a linear range of $0.5-20 \mu \mathrm{M}$ for PhSH. Moreover, probe 56 can be employed for quantitative chemiluminescent monitoring of $\mathrm{PhSH}$ in plasma samples without the addition of luciferase or DMSO.
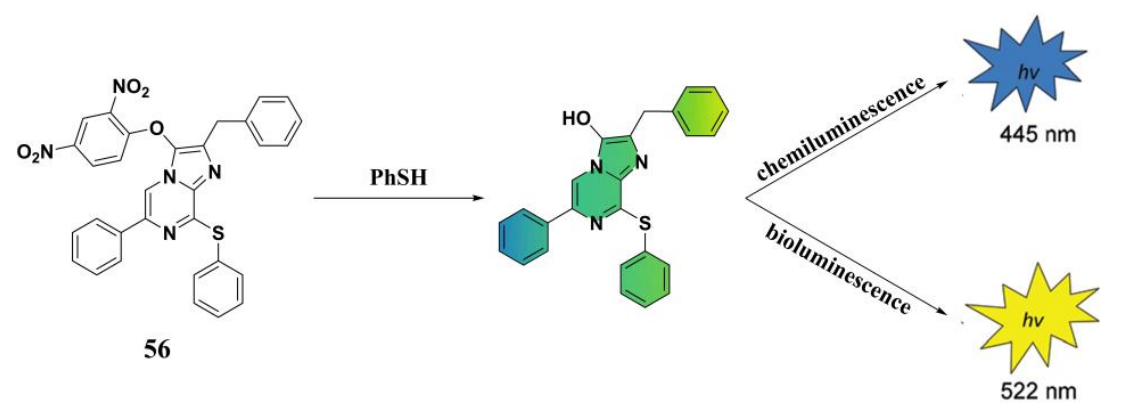

Figure 23. The chemiluminescent and bioluminescent sensing of probe 56 for $\mathrm{PhSH}$.

Electrochemiluminescence (also referred to as electrogenerated chemiluminescence, ECL) sensors drew a great deal of attention due to their distinct advantages such as high sensitivity and real-time analysis [135]. The commonly used ECL luminophores include transition-metal complexes, polyaromatic hydrocarbons, and semiconductor nanocrystals [136]. Among them, transition-metal complexes (i.e., $\mathrm{Ru}, \mathrm{Ir}$, and $\mathrm{Os}$ ) are particularly attractive because of their wide variety of structures and photophysics properties. Using 1-phenylisoquinoline $/ 4^{\prime}$-formyl-1-phenylisoquinoline and acetylacetone as the ligands, Hong et al. developed two cyclometalated iridium(III) complexes $(57,58)$ as both photoluminescence (PL) and ECL probes for sensing PhSH [137]. The structures and ECL sensing mechanisms of these probes are shown in Figure 24. Probe 58 contained an electron-withdrawing formyl group on the quinoline ligand and, thus, displayed faster kinetics and higher sensitivity for responding to PhSH compared with probe 57 . The ECL sensing process involved four steps (i.e., probe 58): (i) PhSH-mediated thiolysis of dinitrophenyl ether and the release of the Ir-based luminophore; (ii) oxidation of probe 58 at Pt electrode to generate (58-DNP) ${ }^{\bullet+}$; (iii) one-electron transfer from the tripropylamine radical $\operatorname{TPrA}^{\bullet}$ to $(\mathbf{5 8}-\mathrm{DNP})^{\bullet+}$ to afford (58-DNP) ${ }^{*}$; (iv) excited-state (58-DNP) ${ }^{*}$ emission of light. The sensing mechanism was also confirmed by density functional theory (DFT) calculations via theoretically predicting highest occupied molecular orbital (HOMO) and lowest unoccupied molecular orbital (LUMO) energies of different species. In a mixed solvent of aqueous HEPES buffer and $\mathrm{CH}_{3} \mathrm{CN}(1: 1, v / v, 10 \mathrm{mM}, \mathrm{pH} 7.4$, containing TprA (tripropylamine) as the co-reactant and TBAP (tetrabutylammonium perchlorate) as the supporting electrolyte), probe 58 displayed a sensitive ECL response to PhSH at 1.4 V. Two linear dynamic ranges were obtained between the ECL intensities and PhSH concentration, $0.5-20 \mu \mathrm{M}(y=0.26 x-1.1)$ and $0-100 \mathrm{nM}\left(y=\left(1.7 \times 10^{-2}\right) x+1.0\right)$. The LOD was calculated to be $3.8 \mathrm{nM}$. Competitive analysis revealed that other analytes could not generate any noticeable ECL changes, while remarkable ECL signals could be observed by adding $\mathrm{PhSH}$ to mixtures of probe $\mathbf{5 8}$ with other interference, except for the oxidation-sensitive anion of iodide. 

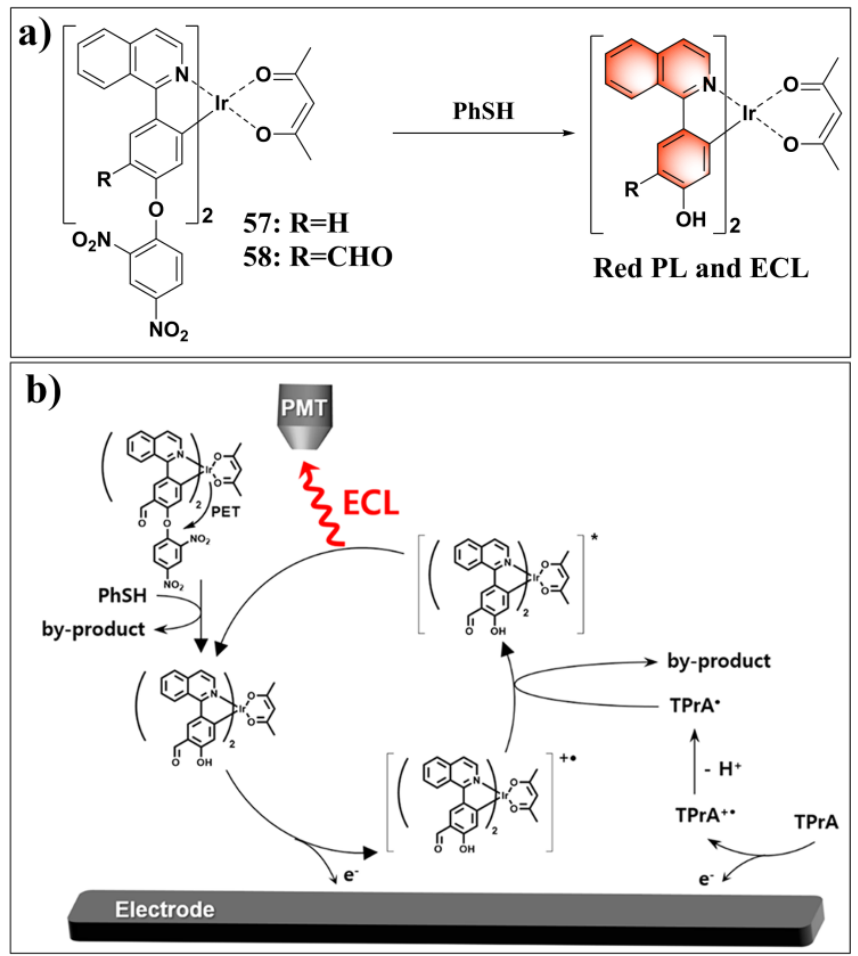

Figure 24. (a) Structures and reactions of probes 57-58 with PhSH. (b) Electrochemiluminescence (ECL) sensing mechanism of probe 58 for PhSH. Reproduced with permission from Reference [137]; copyright American Chemical Society.

By using a well-known $\mathrm{pH}$ indicator, phenolphthalein, as the signaling reporter, Park and Yoon et al. reported a colorimetric probe (59) (Figure 25) for sensing PhSH [138]. Incorporation of dinitrophenyl ether into a number of other fluorophores afforded PhSH probes with different emission colors (Figures 25 and 26): cyan (60 [139]), green (61 [140], 62 [141], 63 [142], 64 [143], 65 [144], 66 [145], and 67 [146]), yellow-green (68 [147] and 69 [148]), orange (70 [142]), red (71 [149], 72 [150], and 73 [151]), and near-infrared (74 [152], 75 [153], and 76 [154]).

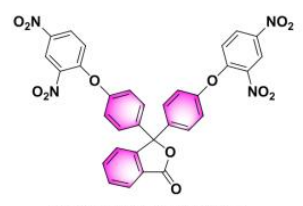

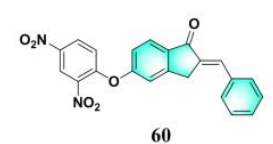

60

Colorimetric probe 59

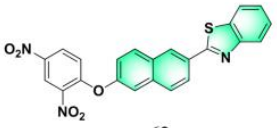

62

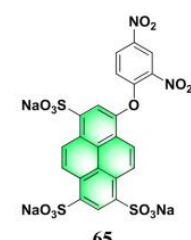

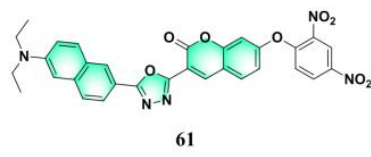

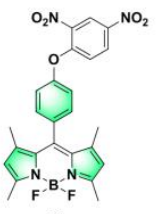

64

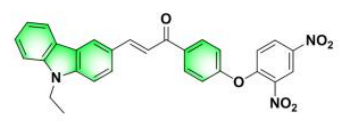

67

Figure 25. Structures of $\mathrm{PhSH}$ probes (59-67). 


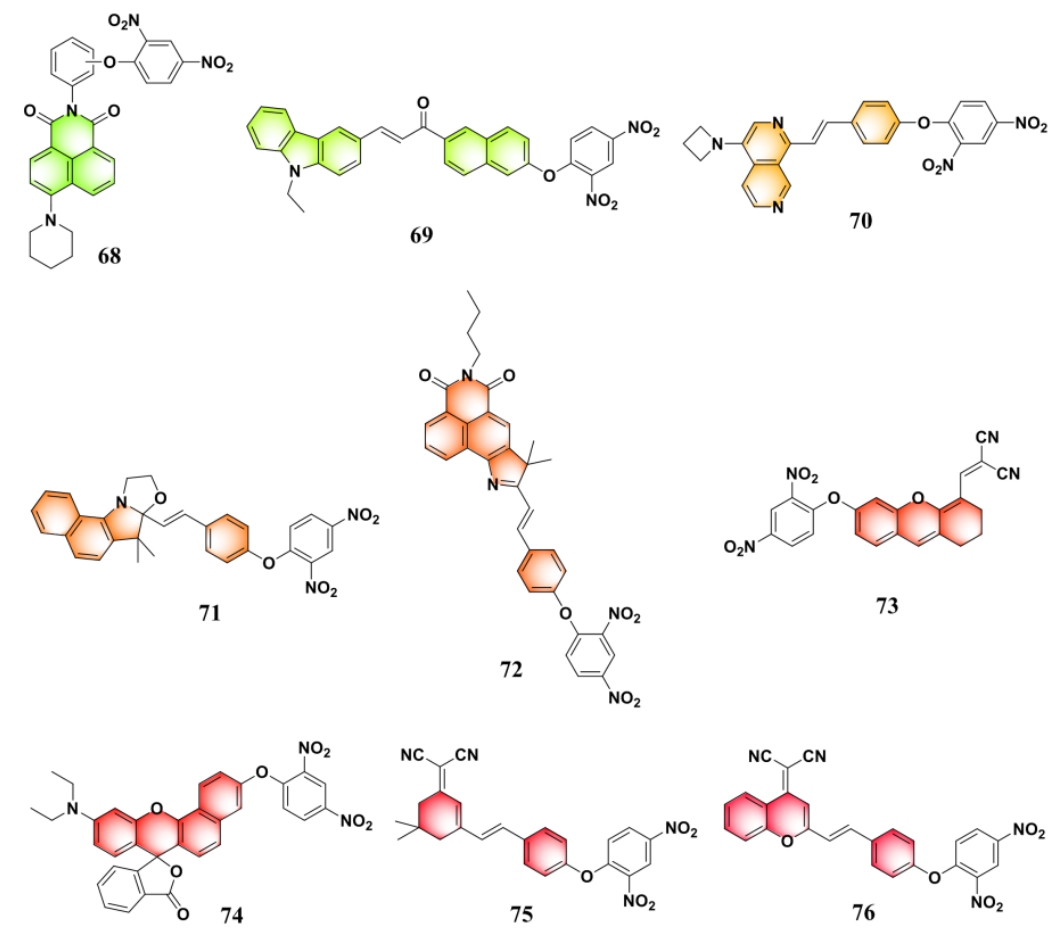

Figure 26. Structures of fluorescent $\mathrm{PhSH}$ probes (68-76).

\section{Probes Based on Other Recognition Moieties}

By utilizing several modified pyrimidine ethers as the recognition moieties and fluorescein/ resorufin as the fluorophores, Wang and Tang et al. established a fluorescent probe library for screening selective probes toward certain sulfhydryl compounds [155]. Among them, probe Flu-3 (77), which was obtained by reacting fluorescein with 4-chloropyrimidine, exhibited high sensitivity and specificity for sensing PhSH. The structure and sensing mechanism of probe 77 for $\mathrm{PhSH}$ is shown in Figure 27. In HEPES buffer solution ( $20 \mathrm{mM}, \mathrm{pH} 7.4$ ), the emission of probe 77 centered at $519 \mathrm{~nm}$, corresponding to the emission of fluorescein, was found to be significantly enhanced upon the addition of PhSH. A good linearity between the fluorescence intensity and the concentration of $\mathrm{PhSH}$ in the range of $0-100 \mu \mathrm{M}$ was obtained, and the LOD was determined to be $1.8 \mu \mathrm{M}$. Probe 77 was also employed for fluorescence imaging of thiophenol in HepG2 cells.

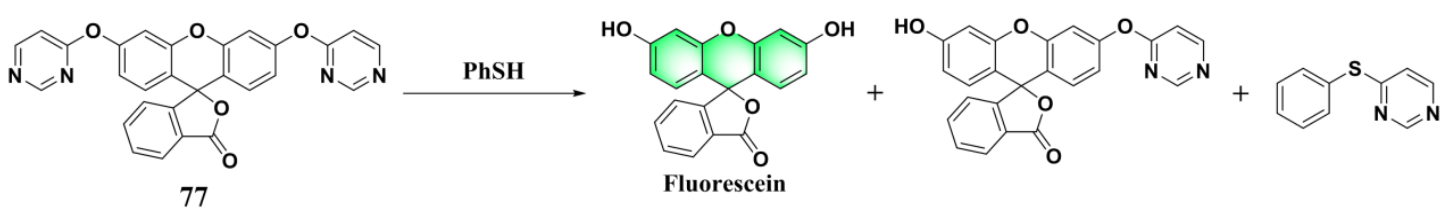

Figure 27. Structure and sensing mechanism of probe 77 for $\mathrm{PhSH}$.

Niu and Yang et al. reported a chlorinated BODIPY-based fluorescent probe (78) (Figure 28) for ratiometric sensing PhSH [156]. In a solution of acetonitrile/HEPES buffer (1:3 v/v, $20 \mathrm{mM}, \mathrm{pH} 7.4)$, the probe displayed an absorption maximum at $518 \mathrm{~nm}$ and a distinct green emission $\left(\lambda_{\mathrm{em}}=540 \mathrm{~nm}\right)$ upon reacting with PhSH via nucleophilic substitution. The absorption band shifted to $558 \mathrm{~nm}$ with the solution color changing from orange to pink (Figure 28b), and the emission band shifted to $580 \mathrm{~nm}$ corresponding to a bright-yellow fluorescence (Figure 28c). The ratio of fluorescence intensities at 581 and $540 \mathrm{~nm}\left(I_{581} / I_{540}\right)$ could remarkably increase (up to 640 -fold) in the presence of an excess amount of PhSH. A good linear relationship was obtained between the fluorescence ratio and concentration of $\mathrm{PhSH}$ in the range of $0-18 \mu \mathrm{M}\left(R^{2}=0.997\right)$. The LOD was determined to be $36.9 \mathrm{nM}$. The probe also displayed excellent selectivity and anti-interference ability for sensing $\mathrm{PhSH}$. Furthermore, probe 
78 was successfully exploited for ratiometric imaging of PhSH in living HeLa cells via observing the intracellular fluorescence in both green and red channels (Figure 28d-k).
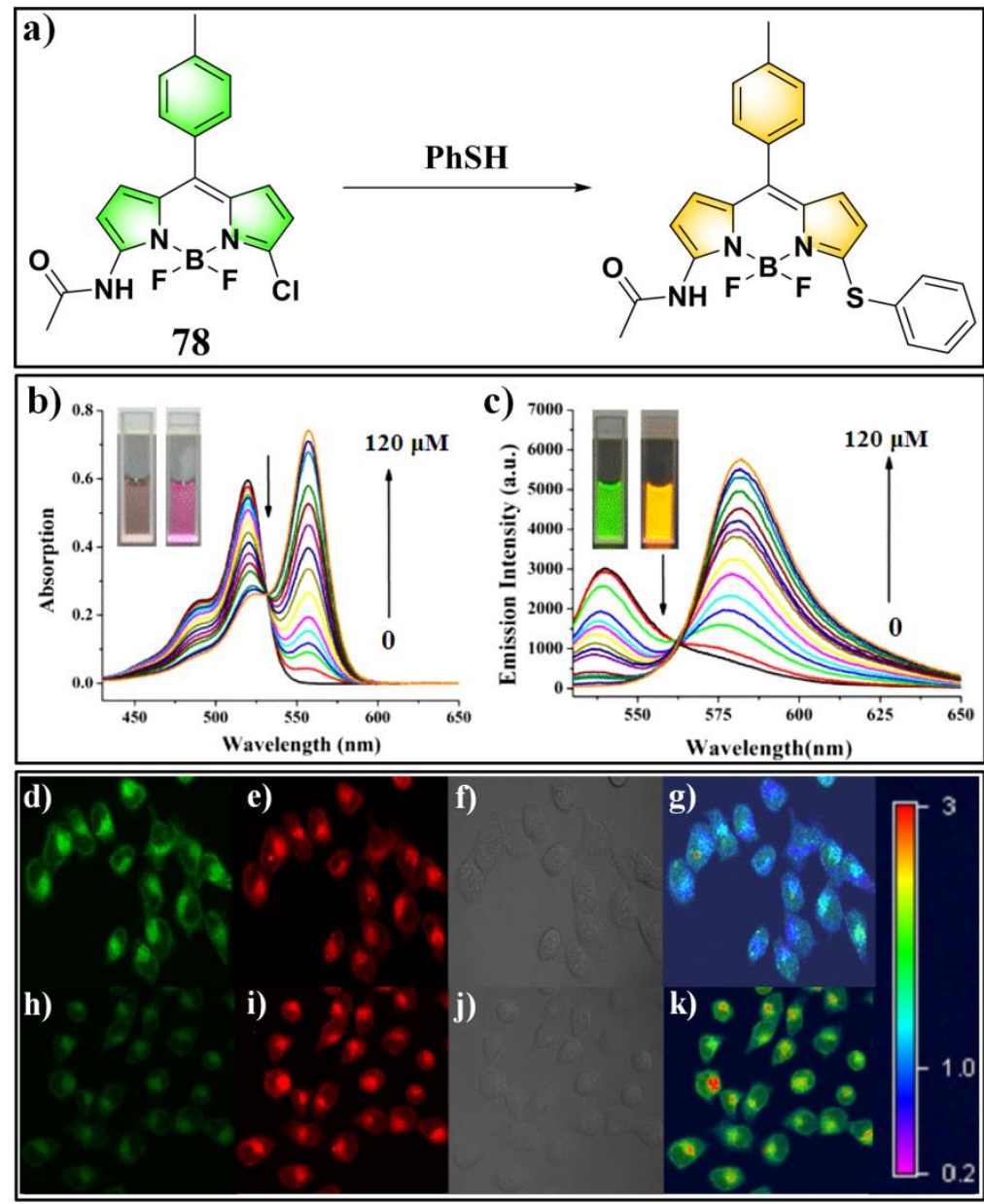

Figure 28. (a) Structure and reaction of probe 78 for PhSH. (b) Absorption and (c) emission spectra of 78 in the presence of $\mathrm{PhSH}$ with different concentrations. (d-k) Confocal fluorescence images of living HeLa cells: $(\mathbf{d}-\mathbf{g})$ cells loaded with probe 78; $(\mathbf{h}-\mathbf{k})$ PhSH-incubated cells loaded with probe 78; (d,h) green channel images (500-550 nm); (e,i) red channel images (570-620 nM); (f,j) bright-field images; (g) ratio image merged from $(\mathbf{d}, \mathbf{e}) ;(\mathbf{k})$ ratio image merged from $(\mathbf{h}, \mathbf{i})$. Reproduced with permission from Reference [156]; copyright 2017 Elsevier B.V., New York, NY, USA.

In previous studies, nitrobenzoxadiazole (NBD)-appended dual-fluorophore (NBD-O-F) systems were artfully employed for differentiating $\mathrm{H}_{2} \mathrm{~S} / \mathrm{GSH}$ and Cys/Hcy (Figure 29a) [157-159]. Typically, thiols can readily react with NBD-O-F via nucleophilic aromatic substitution to produce NBD-SR (or NBD-SH for $\mathrm{H}_{2} \mathrm{~S}$ ) and another free fluorophore (marked as F). In cases of Cys and Hcy, the generated NBD-SR can undergo subsequent intermolecular rearrangement with adjacent amine groups to form emissive NBD-NHR derivatives, while such a process cannot occur for $\mathrm{H}_{2} \mathrm{~S}$ and GSH. Recently, Chen and Zeng et al. synthesized an NBD-O-porphyrin (probe 79) (Figure 29b) by installing NBD onto a porphyrin dye at the aromatic ortho-position [160]. Interestingly, probe $\mathbf{7 9}$ displayed selective turn-on fluorescence toward PhSH. The markedly suppressed reactivities of the probe for other thiols (Cys, Hcy, GSH) can be ascribed to the increased steric hindrance effect of these biothiols. Probe $\mathbf{7 9}$ also showed great sensing performance for PhSH, including fast response (60 s), high sensitivity (LOD = $54 \mathrm{nM}$ ), and deep-red to NIR emission. 

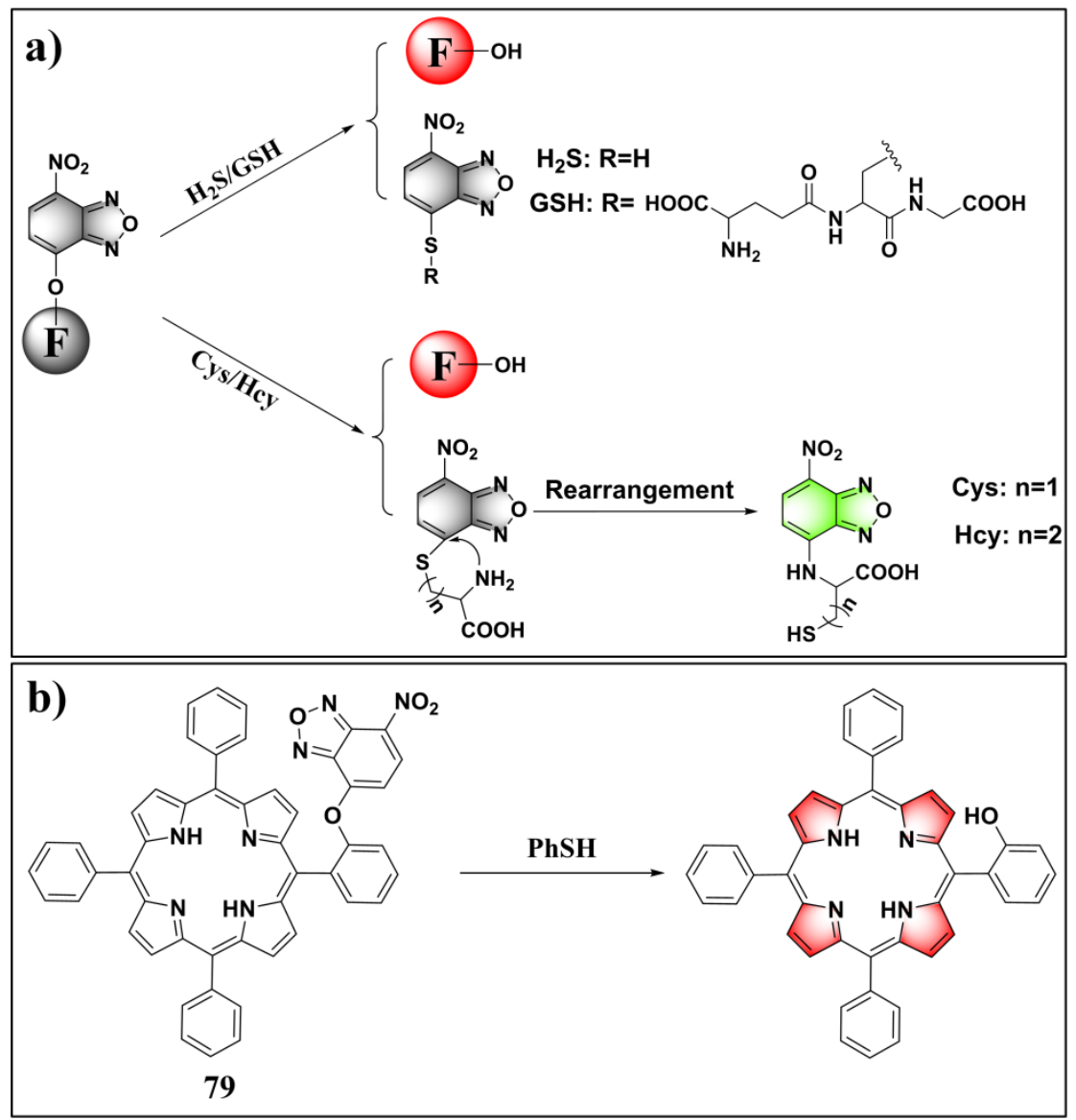

Figure 29. (a) Schematic illustration of nitrobenzoxadiazole (NBD)-appended dual-fluorophore system for differentiating $\mathrm{H}_{2} \mathrm{~S} / \mathrm{GSH}$ and Cys/Hcy. (b) Structure and reaction of probe $\mathbf{7 9}$ for $\mathrm{PhSH}$.

\section{Conclusions}

Since Wang et al. reported the first synthetic chemodosimeter for the selective detection of PhSH in 2007, a great deal of effort was devoted to the development of fluorescent $\mathrm{PhSH}$ probes. In this review, we comprehensively overviewed the recently reported fluorogenic and colorimetric probes for sensing $\mathrm{PhSH}$. Table 1 shows the structures and analytical performances of some representative probes for sensing PhSH. Notably, luminophores for chemiluminescence sensing of $\mathrm{PhSH}$ were also devised, which could provide a new strategy for extending the applications of synthetic organic probes in other advanced analytical techniques. By adapting various fluorophores, the developed fluorescent $\mathrm{PhSH}$ probes cover spectral regions from ultraviolet to visible and even near-infrared. Some of these fluorescent probes displayed superior analytical performance, such as high sensitivity, fast response, good specificity, high photo- and chemical stabilities, high quantum yields, etc. Although substantial and rapid progress $\mathrm{h}$ was made in the development of effective fluorescent probes for $\mathrm{PhSH}$, the recognition moieties and reaction types of these probes for $\mathrm{PhSH}$ are still quite limited. Most of these probes were obtained by directly appending amine- or hydroxyl-containing fluorophores with the recognition unit of 2,4-dinitrobenzenesulfonyl/2,4-dinitrophenyl groups, which have dramatic fluorescence-quenching effects. Upon PhSH-mediated cleavage of the recognition unit, the probe system can restore the fluorescence spectra of the fluorophore; thus, these probes display "turn-on" fluorescence behavior. Future efforts can aim at exploring new appropriate electron-deficient or potential leaving groups as the recognition moieties to sensitively respond to $\mathrm{PhSH}$. Introducing a self-immolative linker between the fluorophore and the recognition unit is also a feasible approach for establishing ratiometric probes. 
Table 1. Comparison of fluorescent probes for thiophenol (PhSH).

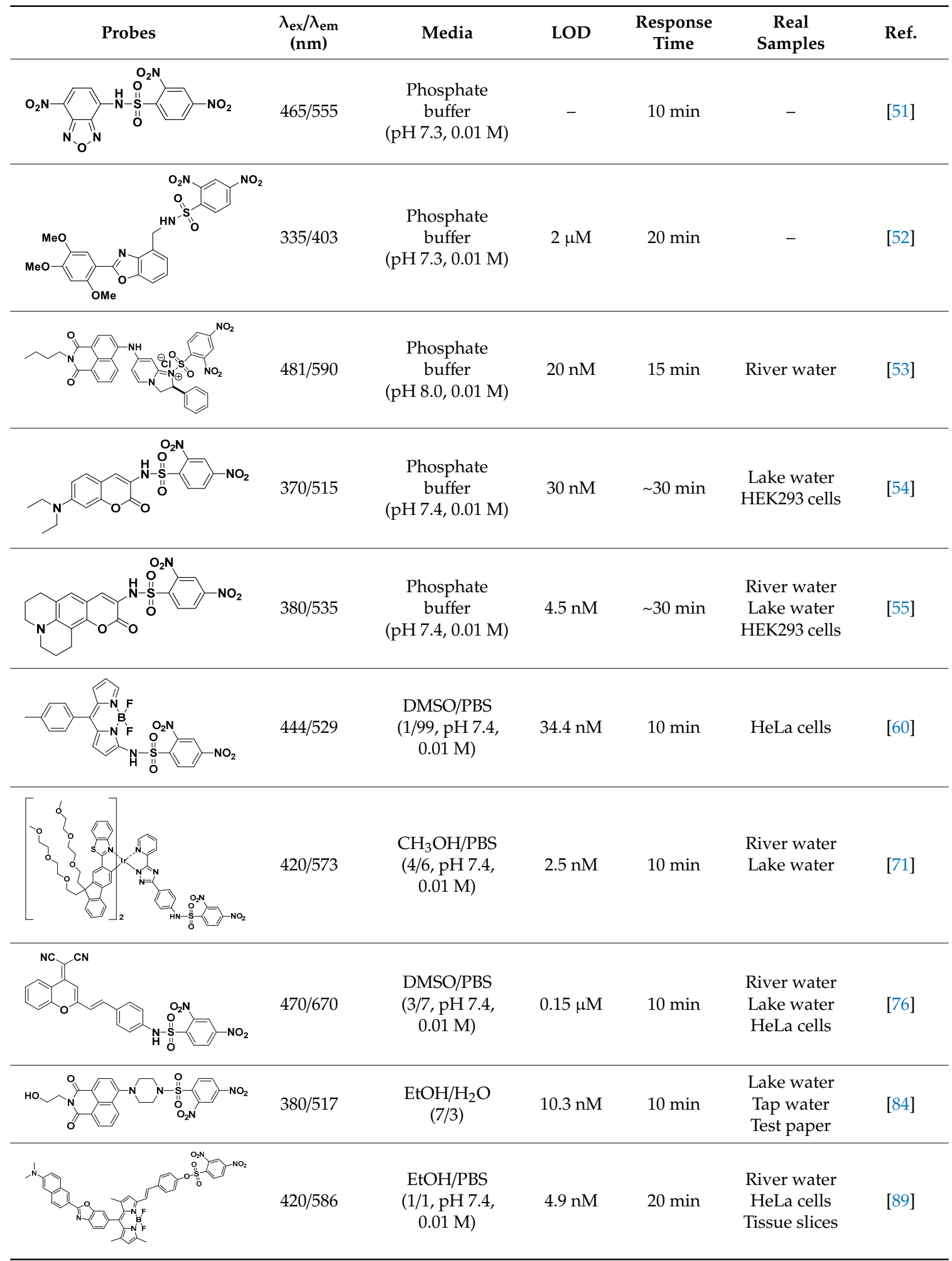


Table 1. Cont.

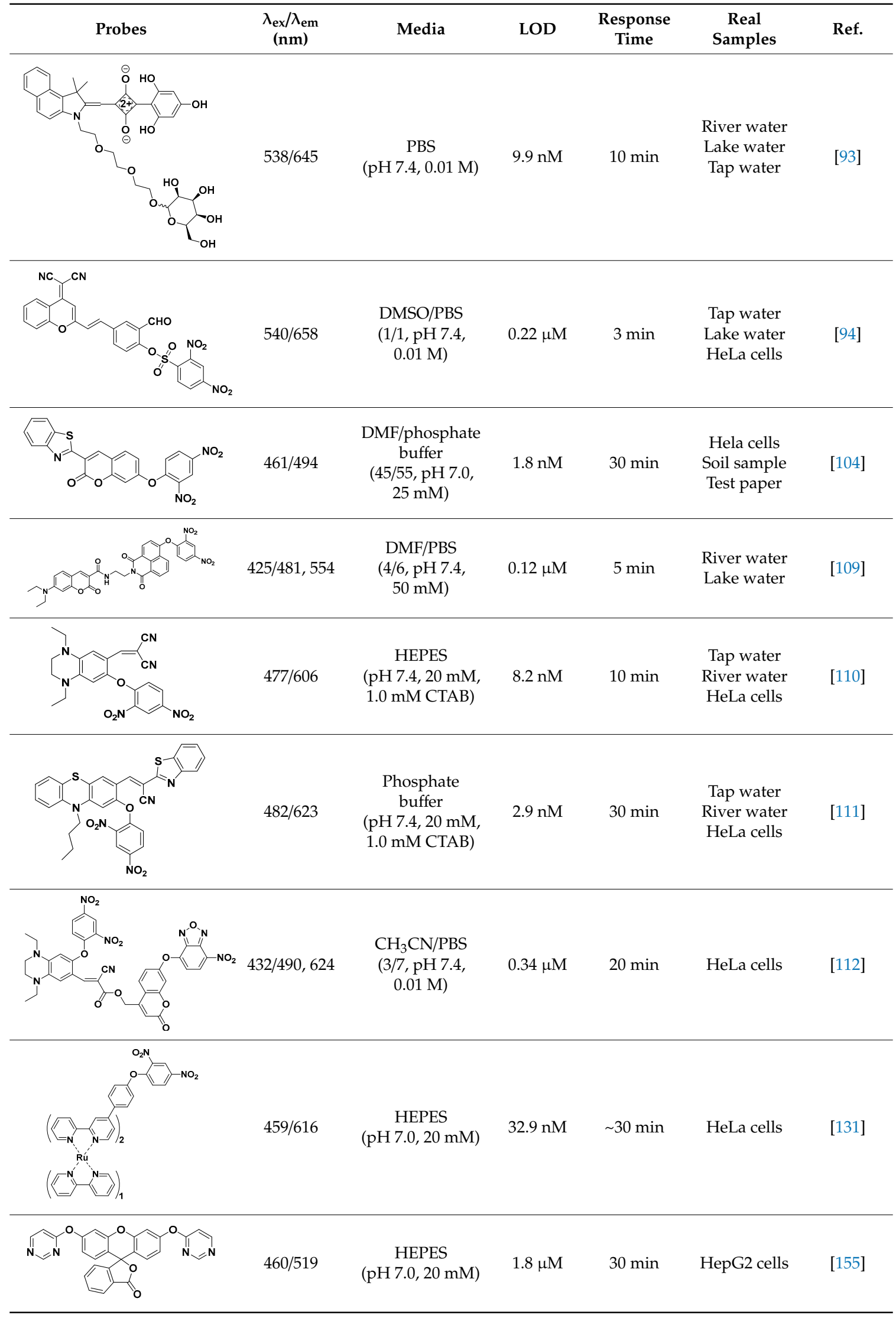


Table 1. Cont.

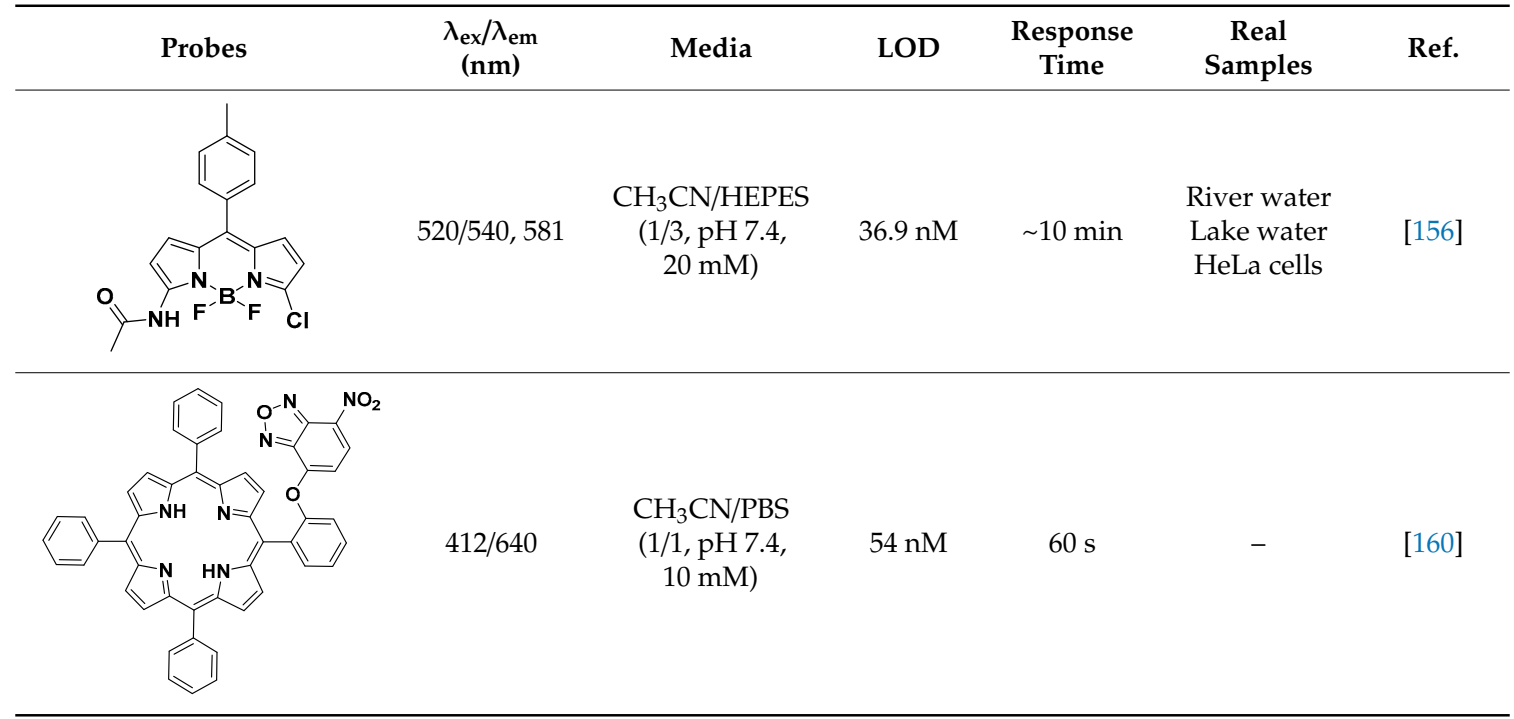

LOD: limit of detection, DMSO: dimethyl sulfoxide, PBS: phosphate buffer saline, DMF: N,N-dimethylformamide, HEPES: N-2-hydroxyethylpiperazine-N-2'-ethanesulfonic acid, CTAB: cetyltrimethylammonium bromide

Author Contributions: Conceptualization, Y.H. and S.C.; writing-original draft preparation, Y.H.; writing-review and editing, S.C., Q.Y., L.Y., Y.Z. and M.X.; project administration, Y.H. and S.C.; funding acquisition, Y.H. and M.X.

Funding: This work was funded by the National Natural Science Foundation of China (Project No. 21804085).

Conflicts of Interest: The authors declare no conflicts of interest.

\section{Abbreviations}

$\begin{array}{ll}\text { PhSH } & \text { thiophenol } \\ \text { DNPS } & \text { 2,4-dinitrobenzenesulfonyl } \\ \text { DNP } & \text { 2,4-dinitrophenyl } \\ \text { GSH } & \text { glutathione } \\ \text { Cys } & \text { cysteine } \\ \text { Hcy } & \text { homocysteine } \\ \text { NBD } & \text { 7-nitro-2,1,3-benzoxadiazole } \\ \text { LOD } & \text { limit of detection } \\ \text { SNAr } & \text { nucleophilic aromatic substitution } \\ \text { PET } & \text { photoinduced electron transfer } \\ \text { GC-FPD } & \text { gas chromatography-flame photometric detector } \\ \text { BODIPY } & \text { boron dipyrromethene difluoride } \\ \text { DMSO } & \text { dimethyl sulfoxide } \\ \text { NIR } & \text { near-infrared } \\ \text { NMR } & \text { nuclear magnetic resonance } \\ \text { MS } & \text { mass spectroscopy } \\ \text { TBET } & \text { through-bond energy transfer } \\ \text { HEPES } & \text { N-2-hydroxyethylpiperazine-N-2'-ethanesulfonic acid } \\ \text { MeOH } & \text { methanol } \\ \text { DMF } & \text { N,N-dimethylformamide } \\ \text { FRET } & \text { fluorescence resonance energy transfer } \\ \text { HPLC } & \text { high-performance liquid chromatography } \\ \text { ESIPT } & \text { excited-state intramolecular proton transfer } \\ \text { Bpy } & \text { 2,2'-bipyridine } \\ \text { ECL } & \text { electrogenerated chemiluminescence } \\ \text { TprA } & \text { tripropylamine } \\ & \end{array}$


TBAP tetrabutylammonium perchlorate

PBS phosphate buffer saline

CTAB cetyltrimethylammonium bromide

\section{References}

1. Yang, L.; Feng, J.-K.; Liao, Y.; Ren, A.-M. A theoretical investigation on the electronic and optical properties of $\pi$-conjugated copolymers with an efficient electron-accepting unit bithieno [3,2-b:2' $3^{\prime}$-e]pyridine. Polymer 2005, 46, 9955-9964. [CrossRef]

2. Wang, J.F.; Shoup, T.M.; Brownell, A.L.; Zhang, Z.D. Improved synthesis of the thiophenol precursor N-(4-chloro-3-mercaptophenyl)picolinamide for making the mGluR4 PET ligands. Tetrahedron 2019, 75, 3917-3922. [CrossRef]

3. Maddox, S.M.; Dawson, G.A.; Rochester, N.C.; Ayonon, A.B.; Moore, C.E.; Rheingold, A.L.; Gustafson, J.L. Enantioselective Synthesis of Biaryl Atropisomers via the Addition of Thiophenols into Aryl-Naphthoquinones. ACS Catal. 2018, 8, 5443-5447. [CrossRef] [PubMed]

4. Hell, T.P.; Lindsay, R.C. Toxicological properties of thio- and alkylphenols causing flavor tainting in fish from the upper Wisconsin River. J. Environ. Sci. Heal. B 1989, 24, 349-360. [CrossRef]

5. Love, J.C.; Estroff, L.A.; Kriebel, J.K.; Nuzzo, R.G.; Whitesides, G.M. Self-Assembled Monolayers of Thiolates on Metals as a Form of Nanotechnology. Chem. Rev. 2005, 105, 1103-1170. [CrossRef]

6. Alamudi, S.H.; Chang, Y.T. Advances in the design of cell-permeable fluorescent probes for applications in live cell imaging. Chem. Commun. 2018, 54, 13641-13653. [CrossRef]

7. Liu, H.W.; Chen, L.L.; Xu, C.Y.; Li, Z.; Zhang, H.Y.; Zhang, X.B.; Tan, W.H. Recent progresses in small-molecule enzymatic fluorescent probes for cancer imaging. Chem. Soc. Rev. 2018, 47, 7140-7180. [CrossRef]

8. Sedgwick, A.C.; Wu, L.L.; Han, H.H.; Bull, S.D.; He, X.P.; James, T.D.; Sessler, J.L.; Tang, B.Z.; Tian, H.; Yoon, J. Excited-state intramolecular proton-transfer (ESIPT) based fluorescence sensors and imaging agents. Chem. Soc. Rev. 2018, 47, 8842-8880. [CrossRef]

9. Wu, D.; Sedgwick, A.C.; Gunnlaugsson, T.; Akkaya, E.U.; Yoon, J.; James, T.D. Fluorescent chemosensors: The past, present and future. Chem. Soc. Rev. 2017, 46, 7105-7123. [CrossRef]

10. Zhang, J.J.; Chai, X.Z.; He, X.P.; Kim, H.J.; Yoon, J.; Tian, H. Fluorogenic probes for disease-relevant enzymes. Chem. Soc. Rev. 2019, 48, 683-722. [CrossRef]

11. Xu, W.; Zeng, Z.B.; Jiang, J.H.; Chang, Y.T.; Yuan, L. Discerning the Chemistry in Individual Organelles with Small-Molecule Fluorescent Probes. Angew. Chem. Int. Ed. 2016, 55, 13658-13699. [CrossRef] [PubMed]

12. Ding, Y.B.; Zhu, W.H.; Xie, Y.S. Development of Ion Chemosensors Based on Porphyrin Analogues. Chem. Rev. 2017, 117, 2203-2256. [CrossRef] [PubMed]

13. Peng, X.X.; Yang, H.P.; Li, C.C.; Zhang, Y.B.; Chen, S.; Long, Y.F. Green and Orange Fluorescent Carbon Dots for Detecting Oral Cancer by Staining Tissue Sections. J. Nanosci. Nanotechnol. 2019, 19, 7509-7516. [CrossRef] [PubMed]

14. Liu, Y.; Zhang, C.H.; Zhang, P.S.; Wang, H.; Liu, J.W.; Wang, S.L.; Zeng, R.J.; Chen, S.; Chen, J. Block copolymer nanoparticles-based fluorescent sensor for ultrasensitive detection of tyrosinase activity and inhibitor. Sens. Actuators B-Chem. 2019, 298, 5. [CrossRef]

15. Xu, J.X.; Yan, F.Y.; Sun, X.D.; Wang, Z.X. Effect of electron-donating/withdrawing substituents on the fluorescence of aniline containing fluorescein Schiff base derivatives. J. Photochem. Photobiol. A-Chem. 2019, 382, 8. [CrossRef]

16. Liu, J.; Zhang, S.L.; Zhu, J.; Liu, X.; Yang, G.Q.; Zhang, X.M. A triarylboron-based binuclear Zn(II) complex as a two-photon fluorescent probe for simultaneous multicolor imaging of the cell membrane, endoplasmic reticulum, and nucleolus. Anal. Bioanal. Chem. 2019, 411, 5223-5231. [CrossRef]

17. Hao, Y.Q.; Chen, S.; Zhou, Y.L.; Zhang, Y.T.; Xu, M.T. Recent Progress in Metal-Organic Framework (MOF) Based Luminescent Chemodosimeters. Nanomaterials 2019, 9, 29. [CrossRef]

18. Qu, P.; Ma, X.H.; Chen, W.S.; Zhu, D.D.; Bai, H.F.; Wei, X.H.; Chen, S.; Xu, M.T. A coumarin-based fluorescent probe for ratiometric detection of hydrazine and its application in living cells. Spectrochim. Acta Part A 2019, 210, 381-386. [CrossRef] 
19. Du, F.K.; Li, M.R.; Wei, Y.Y.; Huang, D.L.; Zhou, Y.; Yang, L.F.; Chen, J.; Liu, S.G.; Tan, X.C. A water-soluble fluorescent probe for detecting creatinine in totally aqueous media and imaging exogenous creatinine in living cells. Anal. Bioanal. Chem. 2019, 411, 9. [CrossRef]

20. Zhang, P.S.; Wang, H.; Zhang, D.; Zeng, X.Y.; Zeng, R.J.; Xiao, L.H.; Tao, H.W.; Long, Y.F.; Yi, P.G.; Chen, J. Two-photon fluorescent probe for lysosome-targetable hypochlorous acid detection within living cells. Sens. Actuators B-Chem. 2018, 255, 2223-2231. [CrossRef]

21. Zhang, P.S.; Tian, Y.; Liu, H.; Ren, J.Y.; Wang, H.; Zeng, R.J.; Long, Y.F.; Chen, J. In vivo imaging of hepatocellular nitric oxide using a hepatocyte-targeting fluorescent sensor. Chem. Commun. 2018, 54, 7231-7234. [CrossRef] [PubMed]

22. Chen, J.; Zhong, W.; Tang, Y.; Wu, Z.; Li, Y.; Yi, P.; Jiang, J. Amphiphilic BODIPY-Based Photoswitchable Fluorescent Polymeric Nanoparticles for Rewritable Patterning and Dual-Color Cell Imaging. Macromolecules 2015, 48, 3500-3508. [CrossRef]

23. Cheng, F.; Wu, X.; Liu, M.; Lon, Y.; Chen, G.; Zeng, R. A porphyrin-based near-infrared fluorescent sensor for sulfur ion detection and its application in living cells. Sens. Actuators B-Chem. 2016, 228, 673-678. [CrossRef]

24. Zhao, Y.-H.; Li, Y.; Long, Y.; Zhou, Z.; Tang, Z.; Deng, K.; Zhang, S. Highly selective fluorescence turn-on determination of fluoride ions via chromogenic aggregation of a silyloxy-functionalized salicylaldehyde azine. Tetrahedron Lett. 2017, 58, 1351-1355. [CrossRef]

25. Nguyen, K.H.; Hao, Y.; Chen, W.; Zhang, Y.; Xu, M.; Yang, M.; Liu, Y.-N. Recent progress in the development of fluorescent probes for hydrazine. Luminescence 2018, 33, 816-836. [CrossRef] [PubMed]

26. Hao, Y.; Zhang, Y.; Ruan, K.; Chen, W.; Zhou, B.; Tan, X.; Wang, Y.; Zhao, L.; Zhang, G.; Qu, P.; et al. A naphthalimide-based chemodosimetric probe for ratiometric detection of hydrazine. Sens. Actuators B-Chem. 2017, 244, 417-424. [CrossRef]

27. Nguyen, K.H.; Hao, Y.; Zeng, K.; Fan, S.; Li, F.; Yuan, S.; Ding, X.; Xu, M.; Liu, Y.-N. A benzothiazole-based fluorescent probe for hypochlorous acid detection and imaging in living cells. Spectrochim. Acta A 2018, 199, 189-193. [CrossRef]

28. Hao, Y.; Chen, W.; Wang, L.; Zhu, X.; Zhang, Y.; Qu, P.; Liu, L.; Zhou, B.; Liu, Y.-N.; Xu, M. A retrievable, water-soluble and biocompatible fluorescent probe for recognition of $\mathrm{Cu}(\mathrm{II})$ and sulfide based on a peptide receptor. Talanta 2015, 143, 307-314. [CrossRef]

29. Hao, Y.; Nguyen, K.H.; Zhang, Y.; Zhang, G.; Fan, S.; Li, F.; Guo, C.; Lu, Y.; Song, X.; Qu, P.; et al. A highly selective and ratiometric fluorescent probe for cyanide by rationally altering the susceptible $\mathrm{H}$-atom. Talanta 2018, 176, 234-241. [CrossRef]

30. Huang, H.W.; Liu, X.Y.; Hu, T.; Chu, P.K. Ultra-sensitive detection of cysteine by gold nanorod assembly. Biosens. Bioelectron. 2010, 25, 2078-2083. [CrossRef]

31. Wang, H.; Zhang, P.S.; Tian, Y.; Zhang, Y.; Yang, H.P.; Chen, S.; Zeng, R.J.; Long, Y.F.; Chen, J. Real-time monitoring of endogenous cysteine levels in living cells using a CD-based ratiometric fluorescent nanoprobe. Anal. Bioanal. Chem. 2018, 410,4379-4386. [CrossRef] [PubMed]

32. Zhao, Q.; Chen, S.N.; Huang, H.W.; Liu, F.P.; Xie, Y.T. Versatile Sensitive Localized Surface Plasmon Resonance Sensor Based on Core-Shell Gold Nanorods for the Determination of Mercury(II) and Cysteine. Anal. Lett. 2014, 47, 295-308. [CrossRef]

33. Liu, H.M.; Mei, G.; Chen, S.; Long, Y.F. High sensitivity cysteine detection using novel fluorescent Ag nanoclusters. Anal. Methods 2017, 9, 3249-3254. [CrossRef]

34. Zhao, Y.H.; Luo, Y.Y.; Wang, H.; Guo, T.; Zhou, H.B.; Tan, H.L.; Zhou, Z.H.; Long, Y.F.; Tang, Z.L. A New Fluorescent Probe Based on Aggregation Induced Emission for Selective and Quantitative Determination of Copper(II) and its Further Application to Cysteine Detection. ChemistrySelect 2018, 3, 1521-1526. [CrossRef]

35. Chen, S.; Fan, Y.; Yang, Y.; Ye, L.Y.; Long, Y.F. Determination of Cysteine Based on Fluorescence Enhancement of CdS Quantum Dots with Cd2+ Rich Surface. Chin. J. Anal. Chem. 2012, 40, 173-176. [CrossRef]

36. Chen, J.; Li, Y.; Lv, K.; Zhong, W.B.; Wang, H.; Wu, Z.; Yi, P.G.; Jiang, J.H. Cyclam-functionalized carbon dots sensor for sensitive and selective detection of copper(II) ion and sulfide anion in aqueous media and its imaging in live cells. Sens. Actuators B-Chem. 2016, 224, 298-306. [CrossRef]

37. Hou, X.Y.; Chen, S.; Tang, J.; Long, Y.F. Visual determination of trace Cysteine based on promoted corrosion of triangular silver nanoplates by sodium thiosulfate. Spectrochim. Acta Part A 2014, 125, 285-289. [CrossRef] 
38. Chen, D.P.; Shan, Y.Y.; Li, J.M.; You, J.M.; Sun, X.J.; Qiu, G.Y.S. External Reductant-Free Palladium-Catalyzed Reductive Insertion of Isocyanide: Synthesis of Polysubstituted Pyrroles and Its Applications as a Cysteine Probe. Org. Lett. 2019, 21, 4044-4048. [CrossRef]

39. Li, Y.F.; Zhang, P.; Fu, W.S.; Chen, L.L.; Wu, S.Y.; Long, Y.F.; Wang, Y. Smartphone-based colorimetric assay of antioxidants in red wine using oxidase-mimic MnO2 nanosheets. Analyst 2019, 144, 5479-5485. [CrossRef]

40. Chen, Z.; Li, H.D.; Chu, L.; Liu, C.B.; Luo, S.L. Simple and Sensitive Colorimetric Assay for Pb2+ Based on Glutathione Protected Ag Nanoparticles by Salt Amplification. J. Nanosci. Nanotechnol. 2015, 15, 1480-1485. [CrossRef]

41. Luo, Z.H.; Xu, H.; Ning, B.G.; Guo, Z.B.; Li, N.; Chen, L.N.; Huang, G.B.; Li, C.; Zheng, B.D. Ratiometric Fluorescent Nanoprobe for Highly Sensitive Determination of Mercury Ions. Molecules 2019, $24,2278$. [CrossRef] [PubMed]

42. Ma, X.H.; Hao, Y.Q.; Liu, J.X.; Wu, G.G.; Liu, L. A Green-emitting Fluorescent Probe Based on a Benzothiazole Derivative for Imaging Biothiols in Living Cells. Molecules 2019, 24, 411. [CrossRef] [PubMed]

43. Liu, Z.X.; Zhou, X.; Miao, Y.; Hu, Y.; Kwon, N.; Wu, X.; Yoon, J. A Reversible Fluorescent Probe for Real-Time Quantitative Monitoring of Cellular Glutathione. Angew. Chem. Int. Ed. 2017, 56, 5812-5816. [CrossRef] [PubMed]

44. Wang, F.Y.; Zhou, L.; Zhao, C.C.; Wang, R.; Fei, Q.; Luo, S.H.; Guo, Z.Q.; Tian, H.; Zhu, W.H. A dual-response BODIPY-based fluorescent probe for the discrimination of glutathione from cystein and homocystein. Chem. Sci. 2015, 6, 2584-2589. [CrossRef] [PubMed]

45. Jung, H.S.; Chen, X.Q.; Kim, J.S.; Yoon, J. Recent progress in luminescent and colorimetric chemosensors for detection of thiols. Chem. Soc. Rev. 2013, 42, 6019-6031. [CrossRef] [PubMed]

46. Yin, J.; Kwon, Y.; Kim, D.; Lee, D.; Kim, G.; Hu, Y.; Ryu, J.H.; Yoon, J. Cyanine-Based Fluorescent Probe for Highly Selective Detection of Glutathione in Cell Cultures and Live Mouse Tissues. J. Am. Chem. Soc. 2014, 136, 5351-5358. [CrossRef] [PubMed]

47. Li, Y.; Wang, K.-N.; Liu, B.; Lu, X.-R.; Li, M.-F.; Ji, L.-N.; Mao, Z.-W. Mitochondria-targeted two-photon fluorescent probe for the detection of biothiols in living cells. Sens. Actuators B-Chem. 2018, 255, 193-202. [CrossRef]

48. Lin, V.S.; Chen, W.; Xian, M.; Chang, C.J. Chemical probes for molecular imaging and detection of hydrogen sulfide and reactive sulfur species in biological systems. Chem. Soc. Rev. 2015, 44, 4596-4618. [CrossRef]

49. Niu, L.Y.; Chen, Y.Z.; Zheng, H.R.; Wu, L.Z.; Tung, C.H.; Yang, Q.Z. Design strategies of fluorescent probes for selective detection among biothiols. Chem. Soc. Rev. 2015, 44, 6143-6160. [CrossRef]

50. Chen, X.; Zhou, Y.; Peng, X.; Yoon, J. Fluorescent and colorimetric probes for detection of thiols. Chem. Soc. Rev. 2010, 39, 2120-2135. [CrossRef]

51. Jiang, W.; Fu, Q.; Fan, H.; Ho, J.; Wang, W. A Highly Selective Fluorescent Probe for Thiophenols. Angew. Chem. Int. Ed. 2007, 46, 8445-8448. [CrossRef]

52. Jiang, W.; Cao, Y.; Liu, Y.; Wang, W. Rational design of a highly selective and sensitive fluorescent PET probe for discrimination of thiophenols and aliphatic thiols. Chem. Commun. 2010, 46, 1944-1946. [CrossRef] [PubMed]

53. Wang, Z.; Han, D.-M.; Jia, W.-P.; Zhou, Q.-Z.; Deng, W.-P. Reaction-Based Fluorescent Probe for Selective Discrimination of Thiophenols over Aliphaticthiols and Its Application in Water Samples. Anal. Chem. 2012, 84, 4915-4920. [CrossRef] [PubMed]

54. Li, J.; Zhang, C.-F.; Yang, S.-H.; Yang, W.-C.; Yang, G.-F. A Coumarin-Based Fluorescent Probe for Selective and Sensitive Detection of Thiophenols and Its Application. Anal. Chem. 2014, 86, 3037-3042. [CrossRef]

55. Sun, Q.; Yang, S.-H.; Wu, L.; Yang, W.-C.; Yang, G.-F. A Highly Sensitive and Selective Fluorescent Probe for Thiophenol Designed via a Twist-Blockage Strategy. Anal. Chem. 2016, 88, 2266-2272. [CrossRef] [PubMed]

56. Boens, N.; Leen, V.; Dehaen, W. Fluorescent indicators based on BODIPY. Chem. Soc. Rev. 2012, 41, 1130-1172. [CrossRef]

57. Kowada, T.; Maeda, H.; Kikuchi, K. BODIPY-based probes for the fluorescence imaging of biomolecules in living cells. Chem. Soc. Rev. 2015, 44, 4953-4972. [CrossRef]

58. Chen, Y.S.; Li, L.; Chen, W.J.; Chen, H.Y.; Yin, J. Near-infrared small molecular fluorescent dyes for photothermal therapy. Chin. Chem. Lett. 2019, 30, 1353-1360. [CrossRef] 
59. Kolemen, S.; Akkaya, E.U. Reaction-based BODIPY probes for selective bio-imaging. Coord. Chem. Rev. 2018, 354, 121-134. [CrossRef]

60. Kand, D.; Mishra, P.K.; Saha, T.; Lahiri, M.; Talukdar, P. BODIPY based colorimetric fluorescent probe for selective thiophenol detection: Theoretical and experimental studies. Analyst 2012, 137, 3921-3924. [CrossRef]

61. Shao, X.; Kang, R.; Zhang, Y.; Huang, Z.; Peng, F.; Zhang, J.; Wang, Y.; Pan, F.; Zhang, W.; Zhao, W. Highly Selective and Sensitive 1-Amino BODIPY-Based Red Fluorescent Probe for Thiophenols with High Off-to-On Contrast Ratio. Anal. Chem. 2015, 87, 399-405. [CrossRef] [PubMed]

62. Chen, W.; Zhu, L.; Hao, Y.; Yue, X.; Gai, J.; Xiao, Q.; Huang, S.; Sheng, J.; Song, X. Detection of thiophenol in buffer, in serum, on filter paper strip, and in living cells using a red-emitting amino phenothiazine boranil based fluorescent probe with a large Stokes shift. Tetrahedron 2017, 73, 4529-4537. [CrossRef]

63. Pagidi, S.; Kalluvettukuzhy, N.K.; Thilagar, P. Triarylboron Anchored Luminescent Probes: Selective Detection and Imaging of Thiophenols in the Intracellular Environment. Langmuir 2018, 34, 8170-8177. [CrossRef] [PubMed]

64. Ke, L.B.; Zhang, C.; Liao, X.X.; Qiu, K.Q.; Rees, T.W.; Chen, Y.; Zhao, Z.Z.; Ji, L.N.; Chao, H. Mitochondria-targeted Ir@AuNRs as bifunctional therapeutic agents for hypoxia imaging and photothermal therapy. Chem. Commun. 2019, 55, 10273-10276. [CrossRef] [PubMed]

65. Wu, W.J.; Guan, R.L.; Liao, X.X.; Yan, X.; Rees, T.W.; Ji, L.N.; Chao, H. Bimodal Visualization of Endogenous Nitric Oxide in Lysosomes with a Two-Photon Iridium(III) Phosphorescent Probe. Anal. Chem. 2019, 91, 10266-10272. [CrossRef]

66. Yu, J.; Tan, H.; Meng, F.; Lv, K.; Zhu, W.; Su, S. Benzotriazole-containing donor-acceptor-acceptor type cyclometalated iridium(III) complex for solution-processed near-infrared polymer light emitting diodes. Dyes Pigments 2016, 131, 231-238. [CrossRef]

67. Yu, J.; Xu, C.; Meng, F.; Tan, H.; Li, M.; Zhu, W. Triphenylamine-functionalized iridium(III) complexes for near-infrared phosphorescent organic light emitting diodes. Dyes Pigments 2019, 166, 307-313. [CrossRef]

68. Zhu, J.; Zheng, X.; Tan, H.; Tan, H.; Yang, J.; Yu, J.; Zhu, W. Small molecule acceptors with indacenodithiophene-benzodithiophene-indacenodithiophene as donating cores for solution-processed non-fullerene solar cells. Chem. Phys. Lett. 2019, 726, 7-12. [CrossRef]

69. You, C.; Liu, D.; Meng, F.; Wang, Y.; Yu, J.; Wang, S.; Su, S.; Zhu, W. Iridium(iii) phosphors with rigid fused-heterocyclic chelating architectures for efficient deep-red/near-infrared emissions in polymer light-emitting diodes. J. Mater. Chem. C 2019, 7, 10961-10971. [CrossRef]

70. Li, Y.; Liu, B.; Lu, X.-R.; Li, M.-F.; Ji, L.-N.; Mao, Z.-W. Cyclometalated iridium(iii) N-heterocyclic carbene complexes as potential mitochondrial anticancer and photodynamic agents. Dalton Trans. 2017, 46, 11363-11371. [CrossRef]

71. Xiong, L.; Yang, L.; Luo, S.; Huang, Y.; Lu, Z. Highly sensitive iridium(iii) complex-based phosphorescent probe for thiophenol detection. Dalton Trans. 2017, 46, 13456-13462. [CrossRef] [PubMed]

72. Lu, H.; Zhang, D.; Fan, C.; Guo, Y.; Xia, X.; Pu, S. Iridium (III) complex-based fluorescent probe for detection of thiophenols and its application in water samples. Dyes Pigments 2019, 163, 138-144. [CrossRef]

73. Chernov, K.G.; Redchuk, T.A.; Omelina, E.S.; Verkhushaa, V.V. Near-Infrared Fluorescent Proteins, Biosensors, and Optogenetic Tools Engineered from Phytochromes. Chem. Rev. 2017, 117, 6423-6446. [CrossRef] [PubMed]

74. Cai, Y.; Wei, Z.; Song, C.H.; Tang, C.C.; Han, W.; Dong, X.C. Optical nano-agents in the second near-infrared window for biomedical applications. Chem. Soc. Rev. 2019, 48, 22-37. [CrossRef]

75. Guo, Z.Q.; Park, S.; Yoon, J.; Shin, I. Recent progress in the development of near-infrared fluorescent probes for bioimaging applications. Chem. Soc. Rev. 2014, 43, 16-29. [CrossRef]

76. Yu, D.; Huang, F.; Ding, S.; Feng, G. Near-Infrared Fluorescent Probe for Detection of Thiophenols in Water Samples and Living Cells. Anal. Chem. 2014, 86, 8835-8841. [CrossRef]

77. Zeng, R.; Gao, Q.; Cheng, F.; Yang, Y.; Zhang, P.; Chen, S.; Yang, H.; Chen, J.; Long, Y. A near-infrared fluorescent sensor with large Stokes shift for rapid and highly selective detection of thiophenols in water samples and living cells. Anal. Bioanal. Chem. 2018, 410, 2001-2009. [CrossRef]

78. Hong, J.; Xia, Q.; Feng, W.; Feng, G. A dicyanoisophorone-based near-infrared fluorescent probe and its application for detecting thiophenols in water and living cells. Dyes Pigments 2018, 159, 604-609. [CrossRef] 
79. Cheng, Y.; Ma, F.; Gu, X.; Liu, Z.; Zhang, X.; Xue, T.; Zheng, Y.; Qi, Z. A novel isophorone-based red-emitting/NIR probe for thiophenol and its application in real water sample and vivo. Spectrochim. Acta A 2019, 210, 281-288. [CrossRef]

80. Kand, D.; Mandal, P.S.; Datar, A.; Talukdar, P. Iminocoumarin based fluorophores: Indispensable scaffolds for rapid, selective and sensitive detection of thiophenol. Dyes Pigments 2014, 106, 25-31. [CrossRef]

81. Choi, M.G.; Cho, M.J.; Ryu, H.; Hong, J.; Chang, S.-K. Fluorescence signaling of thiophenol by hydrolysis of dinitrobenzenesulfonamide of 2-(2-aminophenyl)benzothiazole. Dyes Pigments 2017, 143, 123-128. [CrossRef]

82. Shang, H.; Chen, H.; Tang, Y.; Ma, Y.; Lin, W. Development of a two-photon fluorescent turn-on probe with far-red emission for thiophenols and its bioimaging application in living tissues. Biosens. Bioelectron. 2017, 95, 81-86. [CrossRef] [PubMed]

83. Wu, J.; Ye, Z.; Wu, F.; Wang, H.; Zeng, L.; Bao, G.-M. A rhodamine-based fluorescent probe for colorimetric and fluorescence lighting-up determination of toxic thiophenols in environmental water and living cells. Talanta 2018, 181, 239-247. [CrossRef] [PubMed]

84. Zhang, W.; Liu, X.; Zhang, H.; Feng, C.; Liu, C.; Yu, M.; Wei, L.; Li, Z. A fluorescent probe for benzenethiols and its application on test paper, in water samples and living cells. J. Mater. Chem. C 2015, 3, 8248-8254. [CrossRef]

85. Zhang, M.; Leng, T.; Shen, Y.; Wang, C. Reaction-based fluorescent probe for the selective and sensitive detection of thiophenols with a large Stokes shift and its application in water samples. Analyst 2018, 143, 756-760. [CrossRef] [PubMed]

86. Chang, S.; Xiang, K.; Ming, W.; Cheng, X.; Han, C.; Zhang, Z.; Tian, B.; Zhang, J. Ultrasensitive dicyanoisophorone-based near-infrared fluorescent probe for rapid and specific detection of thiophenols in river water. Res. Chem. Intermed. 2018, 44, 5683-5695. [CrossRef]

87. Li, K.-B.; Zhou, D.; He, X.-P.; Chen, G.-R. Ratiometric glyco-probe for transient determination of thiophenol in full aqueous solution and river water. Dyes Pigments 2015, 116, 52-57. [CrossRef]

88. Hu, G.-F.; Cheng, H.-B.; Niu, J.-L.; Zhang, Z.-H.; Wu, H.-C. A multi-responsive molecular switch based on a diarylethene derivative containing dinitrobenzenesulfonic amide groups. Dyes Pigments 2017, 136, 354-360. [CrossRef]

89. Liu, H.-W.; Zhang, X.-B.; Zhang, J.; Wang, Q.-Q.; Hu, X.-X.; Wang, P.; Tan, W. Efficient Two-Photon Fluorescent Probe with Red Emission for Imaging of Thiophenols in Living Cells and Tissues. Anal. Chem. 2015, 87, 8896-8903. [CrossRef]

90. Yuan, L.; Lin, W.Y.; Zheng, K.B.; He, L.W.; Huang, W.M. Far-red to near infrared analyte-responsive fluorescent probes based on organic fluorophore platforms for fluorescence imaging. Chem. Soc. Rev. 2013, 42, 622-661. [CrossRef]

91. Khopkar, S.; Shankarling, G. Synthesis, photophysical properties and applications of NIR absorbing unsymmetrical squaraines: A review. Dyes Pigments 2019, 170. [CrossRef]

92. Xia, G.M.; Wang, H.M. Squaraine dyes: The hierarchical synthesis and its application in optical detection. J. Photochem. Photobiol. C 2017, 31, 84-113. [CrossRef]

93. Xiong, L.; Ma, J.; Huang, Y.; Wang, Z.; Lu, Z. Highly Sensitive Squaraine-Based Water-Soluble Far-Red/Near-Infrared Chromofluorogenic Thiophenol Probe. ACS Sens. 2017, 2, 599-605. [CrossRef] [PubMed]

94. Li, Y.; Su, W.; Zhou, Z.; Huang, Z.; Wu, C.; Yin, P.; Li, H.; Zhang, Y. A dual-response near-infrared fluorescent probe for rapid detecting thiophenol and its application in water samples and bio-imaging. Talanta 2019, 199, 355-360. [CrossRef]

95. Yue, Y.; Huo, F.; Zhang, Y.; Chao, J.; Martínez-Máñez, R.; Yin, C. Curcumin-Based "Enhanced SNAr” Promoted Ultrafast Fluorescent Probe for Thiophenols Detection in Aqueous Solution and in Living Cells. Anal. Chem. 2016, 88, 10499-10503. [CrossRef]

96. Wang, X.-B.; Zhou, J.; Zhang, D.; Wang, B. A very fast 3-hydroxy-coumarin-based fluorescent probe for highly selective and sensitive detection of thiophenols and its application in water samples. Anal. Methods 2016, 8, 6916-6922. [CrossRef]

97. Wang, X.-B.; Hao, X.; Zhang, D.; Jiang, Y. Reaction-based fluorescent turn-on probe for selective detection of thiophenols in aqueous solution and living cells. Dyes Pigments 2017, 142, 167-174. [CrossRef]

98. Zhang, D.; Xu, N.; Xian, L.; Ge, H.; Fan, J.; Du, J.; Peng, X. A BODIPY-based Fluorescent Probe for Thiophenol. Chin. J. Chem. 2018, 36, 119-123. [CrossRef] 
99. An, R.; Wei, P.; Zhang, D.; Su, N. A highly selective 7-hydroxy-3-methyl-benzoxazinone based fluorescent probe for instant detection of thiophenols in environmental samples. Tetrahedron Lett. 2016, 57, 3039-3042. [CrossRef]

100. Wang, H.; Wu, X.; Yang, S.; Tian, H.; Liu, Y.; Sun, B. A rapid and visible colorimetric fluorescent probe for benzenethiol flavor detection. Food Chem. 2019, 286, 322-328. [CrossRef]

101. Hu, X.; Su, W.; Zhou, Q.; Yin, P.; Li, H.; Yao, S. An excited-state intramolecular proton transfer-based probe for the discrimination of thiophenols over aliphatic thiols. Anal. Methods 2016, 8, 1425-1430. [CrossRef]

102. Lv, W.; Chen, Y.; Bian, L.; Chen, X. A new double-emission fluorescent probe for fast detection of thiophenols in aqueous solution and living cells. Talanta 2019, 197, 204-210. [CrossRef] [PubMed]

103. Wu, F.; Wang, H.; Xu, J.; Yuan, H.-Q.; Zeng, L.; Bao, G.-M. A new fluorescent chemodosimeter for ultra-sensitive determination of toxic thiophenols in environmental water samples and cancer cells. Sens. Actuators B-Chem. 2018, 254, 21-29. [CrossRef]

104. Lin, W.; Long, L.; Tan, W. A highly sensitive fluorescent probe for detection of benzenethiols in environmental samples and living cells. Chem. Commun. 2010, 46, 1503-1505. [CrossRef] [PubMed]

105. Lee, M.H.; Kim, J.S.; Sessler, J.L. Small molecule-based ratiometric fluorescence probes for cations, anions, and biomolecules. Chem. Soc. Rev. 2015, 44, 4185-4191. [CrossRef]

106. Bigdeli, A.; Ghasemi, F.; Abbasi-Moayed, S.; Shahrajabian, M.; Fahimi-Kashani, N.; Jafarinejad, S.; Nejad, M.A.F.; Hormozi-Nezhad, M.R. Ratiometric fluorescent nanoprobes for visual detection: Design principles and recent advances-A review. Anal. Chim. Acta 2019, 1079, 30-58. [CrossRef]

107. Zhang, X.J.; Hu, Y.; Yang, X.T.; Tang, Y.Y.; Han, S.Y.; Kang, A.; Deng, H.S.; Chi, Y.M.; Zhu, D.; Lu, Y. FOrster resonance energy transfer (FRET)-based biosensors for biological applications. Biosens. Bioelectron. 2019, 138. [CrossRef]

108. Gui, R.J.; Jin, H.; Bu, X.N.; Fu, Y.X.; Wang, Z.H.; Liu, Q.Y. Recent advances in dual-emission ratiometric fluorescence probes for chemo/biosensing and bioimaging of biomarkers. Coord. Chem. Rev. 2019, 383, 82-103. [CrossRef]

109. Zhai, Q.; Yang, S.; Fang, Y.; Zhang, H.; Feng, G. A new ratiometric fluorescent probe for the detection of thiophenols. RSC Adv. 2015, 5, 94216-94221. [CrossRef]

110. Liu, X.; Qi, F.; Su, Y.; Chen, W.; Yang, L.; Song, X. A red emitting fluorescent probe for instantaneous sensing of thiophenol in both aqueous medium and living cells with a large Stokes shift. J. Mater. Chem. C 2016, 4, 4320-4326. [CrossRef]

111. Chen, W.; Yue, X.; Li, W.; Hao, Y.; Zhang, L.; Zhu, L.; Sheng, J.; Song, X. A phenothiazine coumarin-based red emitting fluorescent probe for nanomolar detection of thiophenol with a large Stokes shift. Sens. Actuators B-Chem. 2017, 245, 702-710. [CrossRef]

112. Yang, L.; Su, Y.; Geng, Y.; Zhang, Y.; Ren, X.; He, L.; Song, X. A Triple-Emission Fluorescent Probe for Discriminatory Detection of Cysteine/Homocysteine, Glutathione/Hydrogen Sulfide, and Thiophenol in Living Cells. ACS Sens. 2018, 3, 1863-1869. [CrossRef] [PubMed]

113. Zhou, P.W.; Han, K. Unraveling the Detailed Mechanism of Excited-State Proton Transfer. Acc. Chem. Res. 2018, 51, 1681-1690. [CrossRef] [PubMed]

114. Liu, X.; Yang, L.; Gao, L.; Chen, W.; Qi, F.; Song, X. A phthalimide-based fluorescent probe for thiophenol detection in water samples and living cells with a large Stokes shift. Tetrahedron 2015, 71, 8285-8289. [CrossRef]

115. Khandare, D.G.; Banerjee, M.; Gupta, R.; Kumar, N.; Ganguly, A.; Singh, D.; Chatterjee, A. Green synthesis of a benzothiazole based 'turn-on' type fluorimetric probe and its use for the selective detection of thiophenols in environmental samples and living cells. RSC Adv. 2016, 6, 52790-52797. [CrossRef]

116. Lin, L.; Zeng, X.; Shen, Y.; Zhu, H.; Qian, Y. An ultrasensitive fluorescent probe for rapid determination of thiophenols. Talanta 2017, 165, 321-325. [CrossRef] [PubMed]

117. Chen, S.; Li, H.; Hou, P. A large stokes shift fluorescent probe for sensing of thiophenols based on imidazo[1,5- $\alpha]$ pyridine in both aqueous medium and living cells. Anal. Chim. Acta 2017, 993, 63-70. [CrossRef]

118. Hou, P.; Wang, J.; Fu, S.; Liu, L.; Chen, S. Highly sensitive fluorescent probe based on a novel phenothiazine dye for detection of thiophenols in real water samples and living cells. Anal. Bioanal. Chem. 2019, 411, 935-942. [CrossRef] 
119. Zielonka, J.; Joseph, J.; Sikora, A.; Hardy, M.; Ouari, O.; Vasquez-Vivar, J.; Cheng, G.; Lopez, M.; Kalyanaraman, B. Mitochondria-Targeted Triphenylphosphonium-Based Compounds: Syntheses, Mechanisms of Action, and Therapeutic and Diagnostic Applications. Chem. Rev. 2017, 117, 10043-10120. [CrossRef]

120. Dickinson, B.C.; Srikun, D.; Chang, C.J. Mitochondrial-targeted fluorescent probes for reactive oxygen species. Curr. Opin. Chem. Biol. 2010, 14, 50-56. [CrossRef]

121. Ren, M.; Zhou, K.; He, L.; Lin, W. Mitochondria and lysosome-targetable fluorescent probes for HOCl: Recent advances and perspectives. J. Mater. Chem. B 2018, 6, 1716-1733. [CrossRef]

122. Liu, X.-L.; Duan, X.-Y.; Du, X.-J.; Song, Q.-H. Quinolinium-Based Fluorescent Probes for the Detection of Thiophenols in Environmental Samples and Living Cells. Chem. Asian. J. 2012, 7, 2696-2702. [CrossRef] [PubMed]

123. Geng, Y.; Tian, H.; Yang, L.; Liu, X.; Song, X. An aqueous methylated chromenoquinoline-based fluorescent probe for instantaneous sensing of thiophenol with a red emission and a large Stokes shift. Sens. Actuators B-Chem. 2018, 273, 1670-1675. [CrossRef]

124. Liu, Q.; Li, A.; Li, X.; Li, B.; Zhang, Y.; Li, J.; Guo, Y. Selective visualization of live-cell mitochondrial thiophenols and their induced oxidative stress process by a rationally designed rhodol-based fluorescent probe. Sens. Actuators B-Chem. 2019, 283, 820-830. [CrossRef]

125. Pan, Y.; Ren, T.-B.; Cheng, D.; Zeng, Z.-B.; Yuan, L.; Zhang, X.-B. A Selective Near-Infrared Fluorescent Probe for In Vivo Imaging of Thiophenols from a Focused Library. Chem. Asian. J. 2016, 11, 3575-3582. [CrossRef]

126. Qiu, K.Q.; Zhu, H.Y.; Rees, T.W.; Ji, L.N.; Zhang, Q.L.; Chao, H. Recent advances in lysosome-targeting luminescent transition metal complexes. Coord. Chem. Rev. 2019, 398, 14. [CrossRef]

127. Wu, S.; Tu, W.J.; Zhao, Y.Q.; Wang, X.Y.; Song, J.; Yang, X.L. Phosphonate-Substituted Ruthenium(II) Bipyridyl Derivative as a Photoelectrochemical Probe for Sensitive and Selective Detection of Mercury(II) in Biofluids. Anal. Chem. 2018, 90, 14423-14432. [CrossRef]

128. Du, Z.B.; Song, B.; Zhang, W.Z.; Duan, C.C.; Wang, Y.L.; Liu, C.L.; Zhang, R.; Yuan, J.L. Quantitative Monitoring and Visualization of Hydrogen Sulfide In Vivo Using a Luminescent Probe Based on a Ruthenium(II) Complex. Angew. Chem. Int. Ed. 2018, 57, 3999-4004. [CrossRef]

129. de la Torre, C.; Toscani, A.; Marin-Hernandez, C.; Robson, J.A.; Terencio, M.C.; White, A.J.P.; Alcaraz, M.J.; Wilton-Ely, J.; Martinez-Manez, R.; Sancenon, F. Ex Vivo Tracking of Endogenous CO with a Ruthenium(II) Complex. J. Am. Chem. Soc. 2017, 139, 18484-18487. [CrossRef]

130. Liu, C.L.; Zhang, R.; Zhang, W.Z.; Liu, J.P.; Wang, Y.L.; Du, Z.B.; Song, B.; Xu, Z.P.; Yuan, J.L. "Dual-Key-and-Lock" Ruthenium Complex Probe for Lysosomal Formaldehyde in Cancer Cells and Tumors. J. Am. Chem. Soc. 2019, 141, 8462-8472. [CrossRef]

131. Zhang, R.; Ye, Z.; Yin, Y.; Wang, G.; Jin, D.; Yuan, J.; Piper, J.A. Developing Red-Emissive Ruthenium(II) Complex-Based Luminescent Probes for Cellular Imaging. Bioconjugate Chem. 2012, 23, 725-733. [CrossRef] [PubMed]

132. Su, T.A.; Bruemmer, K.J.; Chang, C.J. Caged luciferins for bioluminescent activity-based sensing. Curr. Opin. Biotechnol. 2019, 60, 198-204. [CrossRef] [PubMed]

133. Hananya, N.; Shabat, D. A Glowing Trajectory between Bio- and Chemiluminescence: From Luciferin-Based Probes to Triggerable Dioxetanes. Angew. Chem. Int. Ed. 2017, 56, 16454-16463. [CrossRef] [PubMed]

134. Yuan, M.; Ma, X.; Jiang, T.; Zhang, C.; Chen, H.; Gao, Y.; Yang, X.; Du, L.; Li, M. A novel coelenterate luciferin-based luminescent probe for selective and sensitive detection of thiophenols. Org. Biomol. Chem. 2016, 14, 10267-10274. [CrossRef]

135. Liu, Z.; Qi, W.; Xu, G. Recent advances in electrochemiluminescence. Chem. Soc. Rev. 2015, 44, 3117-3142. [CrossRef]

136. Hu, L.; Xu, G. Applications and trends in electrochemiluminescence. Chem. Soc. Rev. 2010, 39, 3275-3304. [CrossRef]

137. Kim, K.-R.; Kim, H.J.; Hong, J.-I. Electrogenerated Chemiluminescent Chemodosimeter Based on a Cyclometalated Iridium(III) Complex for Sensitive Detection of Thiophenol. Anal. Chem. 2019, 91, 1353-1359. [CrossRef]

138. Kim, H.; Swamy, K.M.K.; Kwon, N.; Kim, Y.; Park, S.; Yoon, J. Colorimetric Detection of Thiophenol Based on a Phenolphthalein Derivative and Its Application as a Molecular Logic Gate. ChemPhysChem 2017, 18, 1752-1754. [CrossRef] 
139. Li, Z.; Liu, C.; Yu, C.; Yuan, R.; Jia, P.; Wang, Z.; Duan, Q.; Zhu, H.; Zhu, B.; Sheng, W. A water-soluble and highly specific fluorescent probe for imaging thiophenols in living cells and zebrafish. New J. Chem. 2019, 43, 6746-6752. [CrossRef]

140. Zhou, L.; Lin, Q.; Liu, S.; Tan, Y.; Sun, H. Molecular engineering of d-A-d-based non-linearity fluorescent probe for quick detection of thiophenol in living cells and tissues. Sens. Actuators B-Chem. 2017, 244, 958-964. [CrossRef]

141. Ma, Q.; Xu, J.; Zhang, X.; Zhou, L.; Liu, H.; Zhang, J. A naphthalene-based two-photon fluorescent probe for selective and sensitive detection of thiophenols. Sens. Actuators B-Chem. 2016, 229, 434-440. [CrossRef]

142. Ren, R.; Xu, H.-C.; Dong, H.; Peng, H.-T.; Wu, P.-P.; Qiu, Y.; Yang, S.-G.; Sun, Q.; She, N.-F. Ultrafast 2,7-Naphthyridine-Based fluorescent probe for detection of thiophenol with a remarkable Stokes shift and its application In vitro and in vivo. Talanta 2019, 205, 120067. [CrossRef]

143. Zhang, D.; Xu, N.; Li, H.; Yao, Q.; Xu, F.; Fan, J.; Du, J.; Peng, X. Probing Thiophenol Pollutant in Solutions and Cells with BODIPY-Based Fluorescent Probe. Ind. Eng. Chem. Res. 2017, 56, 9303-9309. [CrossRef]

144. Yao, Z.; Ge, W.; Guo, M.; Xiao, K.; Qiao, Y.; Cao, Z.; Wu, H.-C. Ultrasensitive detection of thiophenol based on a water-soluble pyrenyl probe. Talanta 2018, 185, 146-150. [CrossRef]

145. Yang, L.; Liu, Y.; Li, Y.; Wang, H.; Zhang, H.; Xu, J.; Ji, L.; Wang, Q.; He, G. A highly sensitive fluorescence probe for thiophenol in living cells via a substitution-cyclization strategy. Tetrahedron 2019, 75, 130538. [CrossRef]

146. Liu, H.; Guo, C.; Guo, S.; Wang, L.; Shi, D. Design and Synthesis of a Fluorescent Probe with a Large Stokes Shift for Detecting Thiophenols and Its Application in Water Samples and Living Cells. Molecules 2019, 24, 375. [CrossRef]

147. Kand, D.; Mandal, P.S.; Saha, T.; Talukdar, P. Structural imposition on the off-on response of naphthalimide based probes for selective thiophenol sensing. RSC Adv. 2014, 4, 59579-59586. [CrossRef]

148. Liu, H.; Guo, C.; Guo, S.; Fan, J.; Wang, L.; Shi, D. Chalcone-analogue fluorescent probes for detecting thiophenols in seawater samples. Talanta 2019, 201, 301-308. [CrossRef]

149. Yin, G.; Yu, T.; Niu, T.; Yin, P.; Chen, H.; Zhang, Y.; Li, H.; Yao, S. A novel fluorescence turn-on probe for the selective detection of thiophenols by caged benzooxazolidinoindocyanine. RSC Adv. 2017, 7, 46148-46154. [CrossRef]

150. Zhou, S.; Rong, Y.; Wang, H.; Liu, X.; Wei, L.; Song, X. A naphthalimide-indole fused chromophore-based fluorescent probe for instantaneous detection of thiophenol with a red emission and a large Stokes shift. Sens. Actuators B-Chem. 2018, 276, 136-141. [CrossRef]

151. Sun, X.; Wang, M.; Lu, Y.; Fan, C.; Lu, Y.; Lu, Z. The construction of an effective far-red fluorescent and colorimetric platform containing a merocyanine core for the specific and visual detection of thiophenol in both aqueous medium and living cells. New J. Chem. 2019, 43, 14139-14144. [CrossRef]

152. Guo, S.-H.; Leng, T.-H.; Wang, K.; Wang, C.-Y.; Shen, Y.-J.; Zhu, W.-H. A colorimetric and turn-on NIR fluorescent probe based on xanthene system for sensitive detection of thiophenol and its application in bioimaging. Talanta 2018, 185, 359-364. [CrossRef]

153. Wang, K.; Zhao, C.-X.; Leng, T.-H.; Wang, C.-Y.; Lu, Y.-X.; Shen, Y.-J.; Zhu, W.-H. Dual quenching strategy for sensitive detection of toxic thiolphenols based on a NIR-illuminant platform with a large Stokes shift. Dyes Pigments 2018, 151, 194-201. [CrossRef]

154. Yu, D.; Zhai, Q.; Yang, S.; Feng, G. A colorimetric and near-infrared fluorescent turn-on probe for in vitro and in vivo detection of thiophenols. Anal. Methods 2015, 7, 7534-7539. [CrossRef]

155. Xie, X.; Li, M.; Tang, F.; Li, Y.; Zhang, L.; Jiao, X.; Wang, X.; Tang, B. Combinatorial Strategy to Identify Fluorescent Probes for Biothiol and Thiophenol Based on Diversified Pyrimidine Moieties and Their Biological Applications. Anal. Chem. 2017, 89, 3015-3020. [CrossRef]

156. Liu, X.-L.; Niu, L.-Y.; Chen, Y.-Z.; Yang, Y.; Yang, Q.-Z. A ratiometric fluorescent probe based on monochlorinated BODIPY for the discrimination of thiophenols over aliphatic thiols in water samples and in living cells. Sens. Actuators B-Chem. 2017, 252, 470-476. [CrossRef]

157. Hammers, M.D.; Pluth, M.D. Ratiometric Measurement of Hydrogen Sulfide and Cysteine/Homocysteine Ratios Using a Dual-Fluorophore Fragmentation Strategy. Anal. Chem. 2014, 86, 7135-7140. [CrossRef]

158. Chen, W.; Luo, H.; Liu, X.; Foley, J.W.; Song, X. Broadly Applicable Strategy for the Fluorescence Based Detection and Differentiation of Glutathione and Cysteine/Homocysteine: Demonstration in Vitro and in Vivo. Anal. Chem. 2016, 88, 3638-3646. [CrossRef] 
159. He, L.W.; Yang, X.L.; Xu, K.X.; Kong, X.Q.; Lin, W.Y. A multi-signal fluorescent probe for simultaneously distinguishing and sequentially sensing cysteine/homocysteine, glutathione, and hydrogen sulfide in living cells. Chem. Sci. 2017, 8, 6257-6265. [CrossRef]

160. Chen, G.; Tang, M.; Fu, X.; Cheng, F.; Long, Y.; Li, Y.; Jiao, Y.; Zeng, R. A highly sensitive and selective "off-on" porphyrin-based fluorescent sensor for detection of thiophenol. J. Mol. Struct. 2019, 1179, 593-596. [CrossRef]

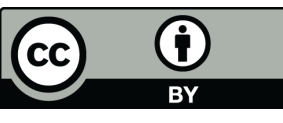

(C) 2019 by the authors. Licensee MDPI, Basel, Switzerland. This article is an open access article distributed under the terms and conditions of the Creative Commons Attribution (CC BY) license (http://creativecommons.org/licenses/by/4.0/). 